\author{
ENERGY DIVISION
}

\title{
STATISTICAL RECOUPLING: \\ A NEW WAY TO BREAK THE LINK \\ BETWEEN ELECTRIC-UTILITY SALES AND REVENUES
}

\section{ERIC HIRST}

September 1993

Sponsored by

Office of Energy Efficiency and Renewable Energy

U.S. Department of Energy

OAK RIDGE NATIONAL LABORATORY

Oak Ridge, Tennessee 37831

managed by

MARTIN MARIETTA ENERGY SYSTEMS, INC.

under contract No. DE-AC05-84-OR21400

for

U.S. DEPARTMENT OF ENERGY 


\section{TABLE OF CONTENTS}

Page

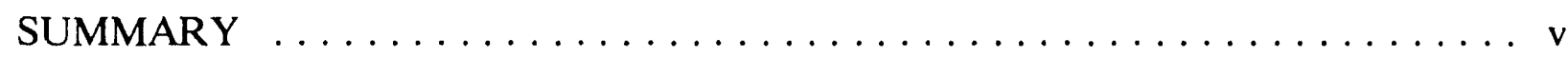

LIST OF ACRONYMS $\ldots \ldots \ldots \ldots \ldots \ldots \ldots \ldots \ldots \ldots \ldots \ldots \ldots \ldots \ldots$ vii

1. INTRODUCTION $\ldots \ldots \ldots \ldots \ldots \ldots \ldots \ldots \ldots \ldots \ldots \ldots \ldots \ldots \ldots \ldots \ldots \ldots$

2. DEFINING AND QUANTIFYING THE PROBLEM $\ldots \ldots \ldots \ldots \ldots \ldots$

3. SOLUTIONS TO THE NET-LOST-REVENUE PROBLEM $\ldots \ldots \ldots \ldots \ldots \ldots 7$

COMMAND-AND-CONTROL REGULATION $\ldots \ldots \ldots \ldots \ldots \ldots 7$

FREQUENT RATE CASES $\ldots \ldots \ldots \ldots \ldots \ldots \ldots \ldots \ldots \ldots \ldots$

ALTERNATIVE RATE DESIGNS $\ldots \ldots \ldots \ldots \ldots \ldots \ldots \ldots \ldots$

NET-LOST-REVENUE ADJUSTMENT MECHANISMS $\ldots \ldots \ldots \ldots \ldots 9$

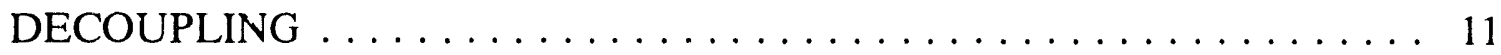

California and New York .................... 11

Washington and Maine ...................... 14

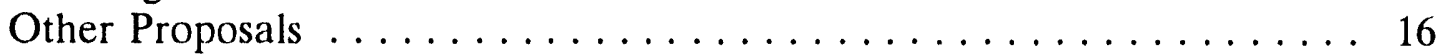

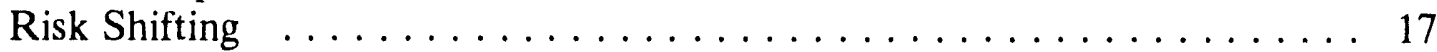

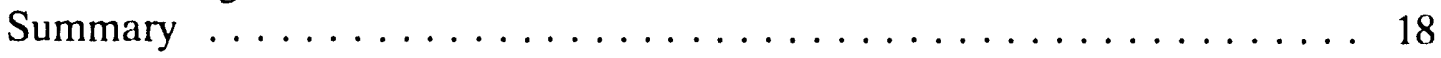

4. STATISTICAL RECOUPLING CONCEPTS $\ldots \ldots \ldots \ldots \ldots \ldots \ldots \ldots$

5. STATISTICAL RECOUPLING MODELS $\ldots \ldots \ldots \ldots \ldots \ldots \ldots \ldots$

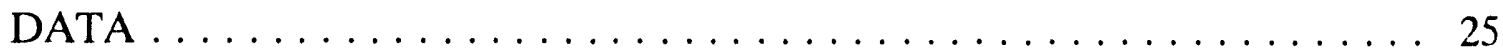

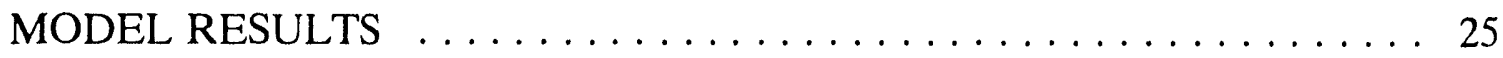

NUMBER OF OBSERVATIONS NEEDED $\ldots \ldots \ldots \ldots \ldots \ldots \ldots$

6. IMPLEMENTING STATISTICAL RECOUPLING $\ldots \ldots \ldots \ldots \ldots \ldots \ldots$

7. OTHER ISSUES FOR STATISTICAL RECOUPLING $\ldots \ldots \ldots \ldots \ldots \ldots 37$

COST-CONTROL AND ECONOMIC-DEVELOPMENT EFFORTS . . . . 37

BIAS IN MODEL SELECTION $\ldots \ldots \ldots \ldots \ldots \ldots \ldots \ldots \ldots \ldots$

EFFECTS OF PAST UTILITY DSM PROGRAMS $\ldots \ldots \ldots \ldots \ldots \ldots . \ldots 41$

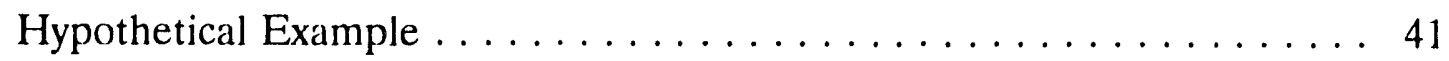

Analysis of Southern California Edison Data . . . . . . . . . . . 43 


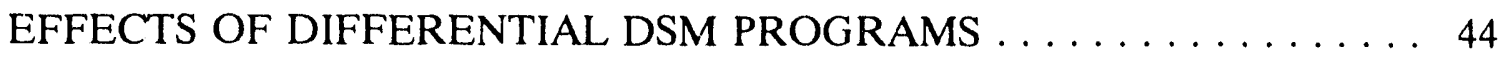

Differences in DSM Across Customer Classes . . . . . . . . . . . . . 44

Differences in Conservation Load Factor . . . . . . . . . . . . . 46

SHIFTS IN ELECTRICITY USE AMONG CUSTOMER CLASSES . . . . . 48

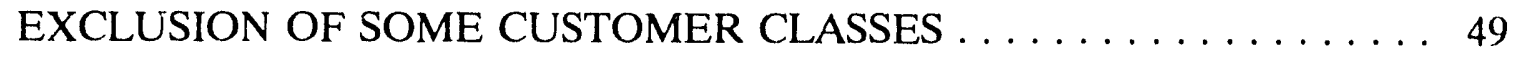

8. CONCLUSIONS .......................... 51

COMPARISON OF STATISTICAL RECOUPLING WITH OTHER

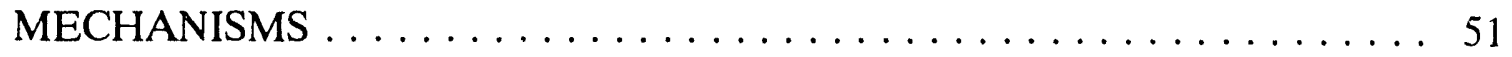

FINAL THOUGHTS $\ldots \ldots \ldots \ldots \ldots \ldots \ldots \ldots \ldots \ldots \ldots \ldots$

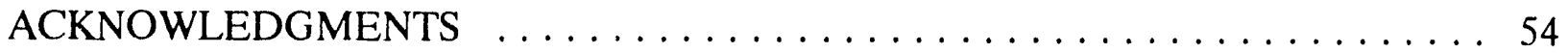

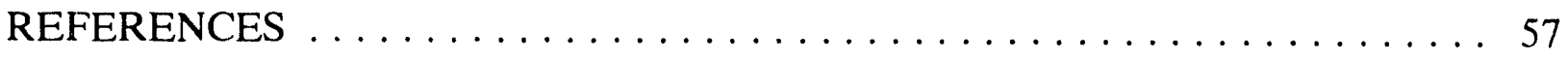

APPENDIX: ALTERNATIVE MODELS OF TOTAL ELECTRICITY USE FOR PACIFICORP $\ldots \ldots \ldots \ldots \ldots \ldots \ldots \ldots \ldots \ldots \ldots \ldots$ 


\section{SUMMARY}

In 1991, U.S. electric utilities spent almost $\$ 1.8$ billion on demand-side management (DSM) programs. These programs cut peak demands $5 \%$ and reduced electricity sales $1 \%$ that year. Utility projections suggest that these reductions will increase to $9 \%$ and $3 \%$, respectively, by the year 2001 .

However, utility DSM efforts vary enormously across the country, concentrated in a few states along the east and west coasts and the upper midwest. To some extent, this concentration is a function of regulatory reforms that remove disincentives to utility shareholders for investments in DSM programs. A key component of these reforms is recovery of the net lost revenues caused by utility DSM programs. These lost revenues occur between rate cases when a utility encourages its customers to improve energy efficiency and cut demand. The reduction in sales means that the utility has less revenue to cover its fixed costs.

This report describes a new method, statistical recoupling (SR), that addresses this net-lost-revenue problem. Like other decoupling approaches, SR breaks the link between electric-utility revenues and sales. Unlike other approaches, SR minimizes changes from traditional regulation. In particular, the risks of revenue swings associated with year-to-year changes in weather and the economy remain with the utility under SR.

Statistical recoupling uses statistical models, based on historical data, that explain retail electricity sales as functions of the number of utility customers, winter and summer weather, the condition of the local economy, electricity price, and perhaps a few other key variables. These models, along with the actual values of the explanatory variables, are then used to estimate "allowed" electricity sales and revenues in future years. For example, a utility might use quarterly data from 1980 through 1992 to estimate the SR models. The models would then be used to determine allowed revenues for 1993, 1994, and 1995.

Five utilities - Nevada Power, New England Electric System, PacifiCorp, Public Service Company of Colorado, and Southern Calírornia Edison - provided data to use in testing this new approach. The empirical results are quite promising (Fig. S-1). With only one exception, the errors are all less than $2 \%$. And the three-year averages for four of the utilities are less than $1 \%$; the three-year average is $1.3 \%$ for Southern California Edison. The lack of patterns across these three years and five utilities suggests that statistical recoupling is a robust method that is likely to yield only small errors from year to year and from utility to utility. 
I examined the number of data points needed to obtain stable results, the price changes likely to occur with this method, its effect on a utility's incentives to control costs and promote economic development, the opportunities to manipulate model selection to achieve desired goals, the effects of past DSM programs, and the effects of DSM programs that differ across customer classes or in load factor. For each issue, statistical recoupling seems to work well. For example, although different statistical models yield different estimates of future electricity use, the differences are small. Therefore - absent perfect foresight about future changes in the explanatory variables - choosing a model to yield desired results is extremely difficult. Also, this approach encourages utilities to promote increased sales only when such sales improve the local economy.

In summary, statistical recoupling appears to be an effective way to break the link between revenues and sales. This approach, when implemented, should free utilities to ambitiously and creatively pursue cost-effective DSM resources in their service areas. Utilities, operating with statistical recoupling, can do so because their shareholders will no longer be penalized by the operation of successful DSM programs.

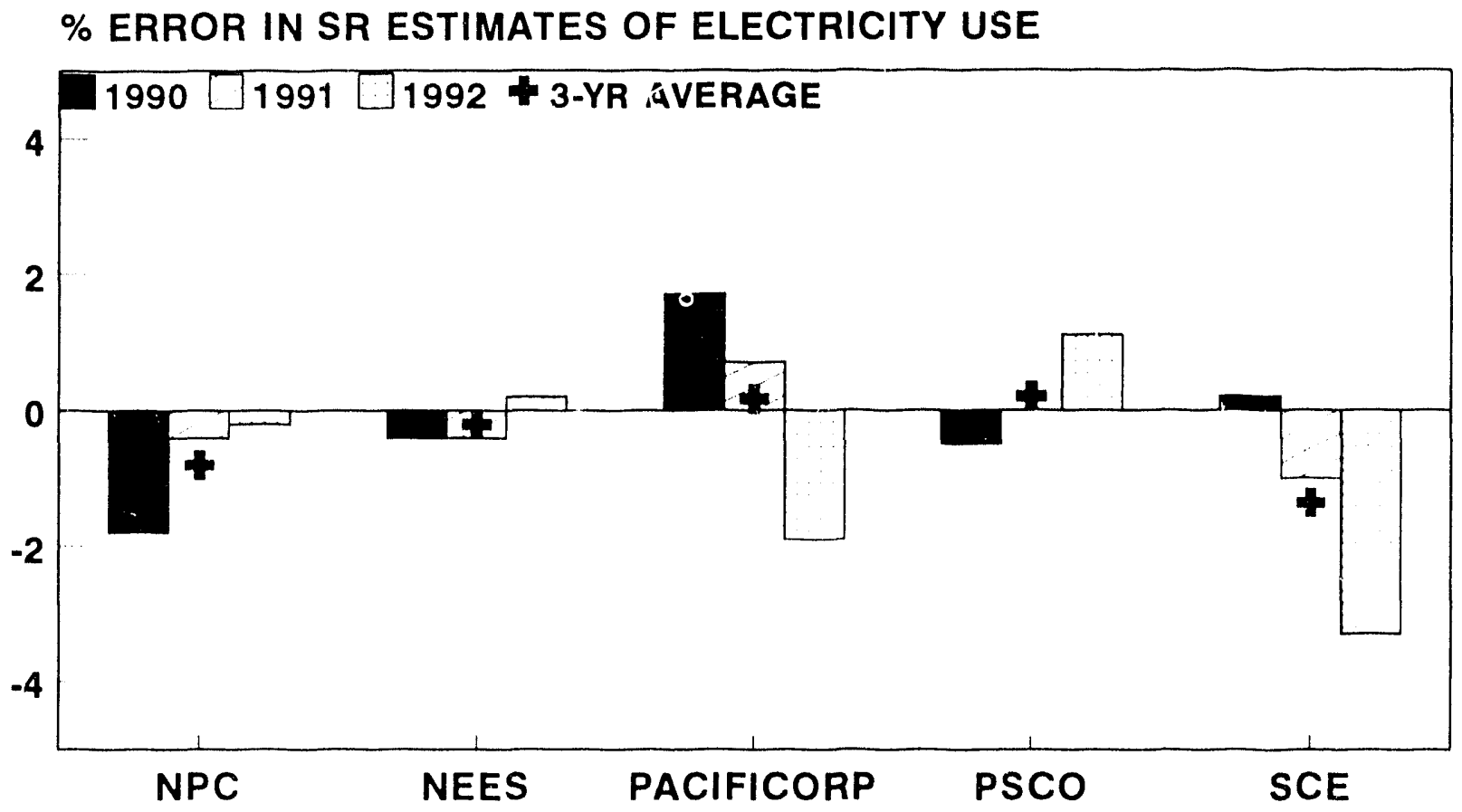

Fig. S-1. Errors in SR estimates of total (residential, commercial, and industrial) retail electricity sales for 1990, 1991, and 1992. The percentage changes in electricity price would be 50 to $75 \%$ of the errors in sales shown here. 


\section{LIST OF ACRONYMS}

CLF Conservation load factor

CMP Central Maine Power Company

DSM Demand-side management

ERAM Electric revenue adjustment mechanism

FAC Fuel-adjustment clause

IRP Integrated resource planning

NEES Massachusetts Electric Company part of the New England Electric System

NPC Nevada Power Company

NLRA Net-lost-revenue adjustment

NPV Net present value

PacifiCorp Utah service area of PacifiCorp

PGE Portland General Electric Company

PG\&E Pacific Gas and Electric Company

PRAM Puget Power's Periodic Rate Adjustment Mechanism

PSCo Public Service Company of Colorado

PUC Public utilities commission

RPC Revenue-per-customer decoupling

SCE Southern California Edison Company

SR Statistical recoupling 


\section{INTRGDUCTION}

The Colorado Public Utilities Commission (1993) recently wrote:

[U]nder traditional regulation, PSCo's [Public Service Company of Colorado, a large utility in the Rocky Mountain region] revenues and profits increase whenever it sells an additional $\mathrm{kWh}$. For similar reasons, PSCo's revenves and profits decline whenever a $\mathrm{kWh}$ is conserved, even if the savings are accomplished at no cost.

[Thus], the financial incentives under which PSCo operates will logically act to hinder the ongoing IRP [integrated resource planning] process. For example, the record of this case shows that utilities in other states have developed load-building marketing programs even though new resource needs were imminent, and have underestimated the long-run DSM [demand-side management] potential.

In other words, utility DSM programs that improve customer energy efficiency create tension between the interests of customers and utility shareholders. Utility customers want the benefits of greater energy efficiency (lower utility bills and improved comfort and productivity), while utility shareholders want the greater earnings associated with higher electricity sales. This conflict can be a major stumbling block to utility implementation of what would otherwise be its "least-cost" resource plan.

State regulation to encourage utility investment in energy efficiency requires three elements (Nadel, Reid, and Wolcott 1992):

- Utility recovery of the costs it incurs to plan, design, implement, and evaluate its DSM programs;

- Recovery of the net lost revenue caused by the energy and demand reductions attributed to the utility's DSM programs; ${ }^{*}$ and

- A financial incentive to the utility to encourage it to run innovative and aggressive DSM programs that capture as much of the cost-effective resource as possible.

While all three components are significant and deserve attention, the net-lost-revenue component is often the most important. It is the most critical both because allowing a utility to recover lost revenues is required to create a level playing field between demand and

"If the utility runs load-building programs, it will enjoy net "gained" revenues. 
supply resources and because it usually represents the largest dollar amount. This report focuses on lost revenues and suggests a new way to solve this problem, called statistical recoupling (SR).

The next chapter defines the net-lost-revenue problem and, using data from a western utility, shows the magnitude of the earnings loss caused by utility DSM programs. Chapter 3 reviews the various approaches that have been used to deal with lost revenues. Chapter 4 presents SR concepts, Chapter 5 presents model results based on data from five utilities throughout the United States, Chapter 6 shows how it would work in practice, and Chapter 7 discusses various issues related to this new approach. Chapter 8 compares the strengths and iimitations of SR with those of other methods that deal with net lost revenues. 


\section{DEFINING AND QUANTIFYING THE PROBLEM}

This chapter quantifies the point that others have made during the past five years: the more electricity a utility sells, the more money it makes for its shareholders (Moskovitz 1989). Conversely, the less electricity it sells (e.g., because it runs energy-efficiency programs for its customers), the more shareholders are hurt.

Utilities periodically file rate cases, and public utility commissions (PUCs) then hold hearings to establish the utility's revenue requirement. Once the revenue requirement is established, the PUC allocates it among customer classes. This allocation is then used to set electricity price structures to collect enough money from each customer class to cover the utility's costs of providing electricity (both energy and demand) to that class.

After rates are set, changes in the amounts of electricity used affect utility revenues. Because fuel and other variable costs vary directly with the amount of electricity sold, a utility automatically collects enough money to just cover these variable costs. Even if prudently incurred fuel costs per $\mathrm{kWh}$ change with time, shareholders neither gain nor lose hecause of the fuel-adjustment clauses (FACs) that operate in many states.

Changes in electricity use also affect the amount of money that a utility collects to cover its fixed costs. Although these costs increase over time (because of inflation, changes in tax rates, and other factors), these increases are - by definition - independent of changes in electricity use. Historically, utilities and PUCs have agreed (at least implicitly) that between-rate-cases increases in revenues associated with load growth would roughly compensate the utility for increases in its fixed costs.

This relationship, however, can produce perverse financial incentives. Consider a $u^{+}$ility with an average retail price of $6 \mathrm{c} / \mathrm{kWh}$. This price reflects $2 \mathrm{c} / \mathrm{kWh}$ of variable costs and $4 \mathrm{c} / \mathrm{kWh}$ of fixed costs. If this utility runs a load-building program that permanently increases electricity use, say by $100 \mathrm{kWh} /$ year, its revenues will go up by $\$ 6 /$ year. This increased revenue is offset by higher fuel costs of $\$ 2 /$ year. Thus, the utility has an extra $\$ 4$ of revenue to offset increases in fixed costs and to increase earnings. The utility will receive this extra $\$ 4$ each year until the next rate case.

If the utility, on the other hand, sponsored an energy-efficiency program that saved its customers $100 \mathrm{kWh} /$ year, its shareholders would lose $\$ 4$ each year until the next rate case. Thus, existing regulation discourages the utility from running energy-efficioncy programs and encourages the utility to sell more electricity. These incentives and disincentives are largely independent of any benefits that customers derive from these programs. 
To quantify these relationships among short-run costs and retail prices and their effect on utility shareholders, Hirst and Blank (1993) developed a simple model that quantifies the effects of higher or lower load growth on shareholder earnings. We used this model to examine the effects of load growth on shareholder earnings for Public Service Company of Colorado, Nevada Power Company, Montana Power Company, and the Utah Division of PacifiCorp. Because the results are quite similar across utilities, I present only the results for Utah. Eto, Stoft, and Belden (1993), using a different approach, show how utility profitability varies with the fraction of total cost that is variable and the ratio of marginal variable cost to average variable cost. Their analysis of data from nearly 160 utilities from 1964 to 1989 shows "excess" annual profits of almost 50 basis points, consistent with the results presented here."

If PacifiCorp's Utah loads grow 1\%/year faster than expected (i.e., at 4 vs $3 \% / y e a r$ or at 2 vs $1 \%$ /year), PacifiCorp shareholders will earn an extra 130 basis points during the three years assumed to occur between rate cases.

If rate cases are conducted more frequently, the effect of higher or lower load growth on earnings is diminished (Fig. 1). For example, if rate cases are conducted annually instead of once every three years, the effect on shareholder earnings is cut in half.

The preceding cases implicitly assumed that load growth is beyond the utility's control (e.g., caused by changes in winter and summer weather or by changes in the rate of economic growth). However, utilities can affect sales through DSM programs, either with load-building or energy-efficiency programs. The following cases examine the effects on utility shareholders of DSM programs that help customers improve energy efficiency and cut electric bills.

Table 1 shows the effects on customers and on PacifiCorp shareholders of three DSM programs. The pilot program operates with a conservation load factor $(\mathrm{CLF})^{*}$ of $10 \%$ and meets $11 \%$ of the growth in energy use. This program provides very small benefits to customers and only a very small penalty to shareholders.

The ramp-up program increases in magnitude from year to year and has a 50\% CLF. This program offsets $22 \%$ of the energy growth between rate cases. Customer benefits and shareholder costs are both increased substantially relative to the pilot program.

"One hundred basis points equals a 1-percentage-point change in the rate of return. For example, an increase of 130 basis points is equivalent to an increase in return on equity from $12.0 \% \mathrm{~W} 13.3 \%$.

"Analogous to the utility's system load factor, the conservation load factor is the ratio of the DSM-program-induced average demand reduction to the peak-demand reduction. 
Table 1. Effects of different types of hypothetical PacifiCorp DSM programs on customers and shareholders

\begin{tabular}{lcccc}
\hline $\begin{array}{c}\text { Type of } \\
\text { DSM } \\
\text { program }\end{array}$ & $\begin{array}{c}\text { Percentage } \\
\text { of energy } \\
\text { growth }\end{array}$ & $\begin{array}{c}\text { Customer } \\
\text { net benefits } \\
\text { (million } \$)\end{array}$ & $\begin{array}{c}\text { Shareholder } \\
\text { effects }\end{array}$ \\
\hline Pilot & 11 & 7 & -6 & -2 \\
Ramp-up & 22 & 41 & -52 & -14 \\
Full-scale & 36 & 80 & -136 & -37 \\
\hline
\end{tabular}

'The benefits of these programs are the avoided capacity costs plus the associated savings in fuel costs and operation and maintenance costs. The costs include the costs of the measures plus the utility's administrative costs to run the program. Net benefits are the difference between benefits and costs.

Finally, the full-scale program offsets $36 \%$ of the three-year growth in energy use. It provides the largest customer benefits, but also has the greatest adverse effect on shareholders. The issue for Utah regulators and others is how to balance the customer benefits of DSM (say the $\$ 80$ million from the full-scale program) against the shareholder penalty ( $\$ 37$ million).

The preceding analyses were all conducted for PacifiCorp's residential customers, who face a energy-only tariff. However, the results are yualitatively the same for PacifiCorp's commercial and industrial customers, who face demand and energy charges. Figure 2 shows the effects of DSM programs with different CLFs for the two types of rate schedules. In both cases, the more $\mathrm{kWh}$ a DSM program saves per $\mathrm{kW}$ of demand reduction, the more PacifiCorp shareholders are penalized. This effect is most pronounced for residential customers but applies to all customer classes.

In summary, current economic regulation: (1) rewards PacifiCorp shareholders for higher load growth regardless of the benefits that customers enjoy from this higher level of electricity use, (2) penalizes PacifiCorp shareholders for DSM programs that promote customer energy efficiency regardless of the economic and environmental benefits such programs provide, and (3) penalizes PacifiCorp shareholders for DSM programs regardless of the customer classes at which the programs are aimed. Indeed, as one utility (PSCo) noted (Gilliam 1992):

If the goal is to make DSM the company's most profitable resource, then full recovery of revenue reductions related to Company sponsored DSM must be the very basis upon which incentives can be layered. To do otherwise is to put DSM at an immediate disadvantage at the starting point. ... Less than full compensation for lost revenue, net of the variable costs, places DSM activities at a distinct disadvantage vis a vis a supply side resource. The Company seeks to place both resources on equal footing. 


\section{CHANGE IN BASIS POINTS}

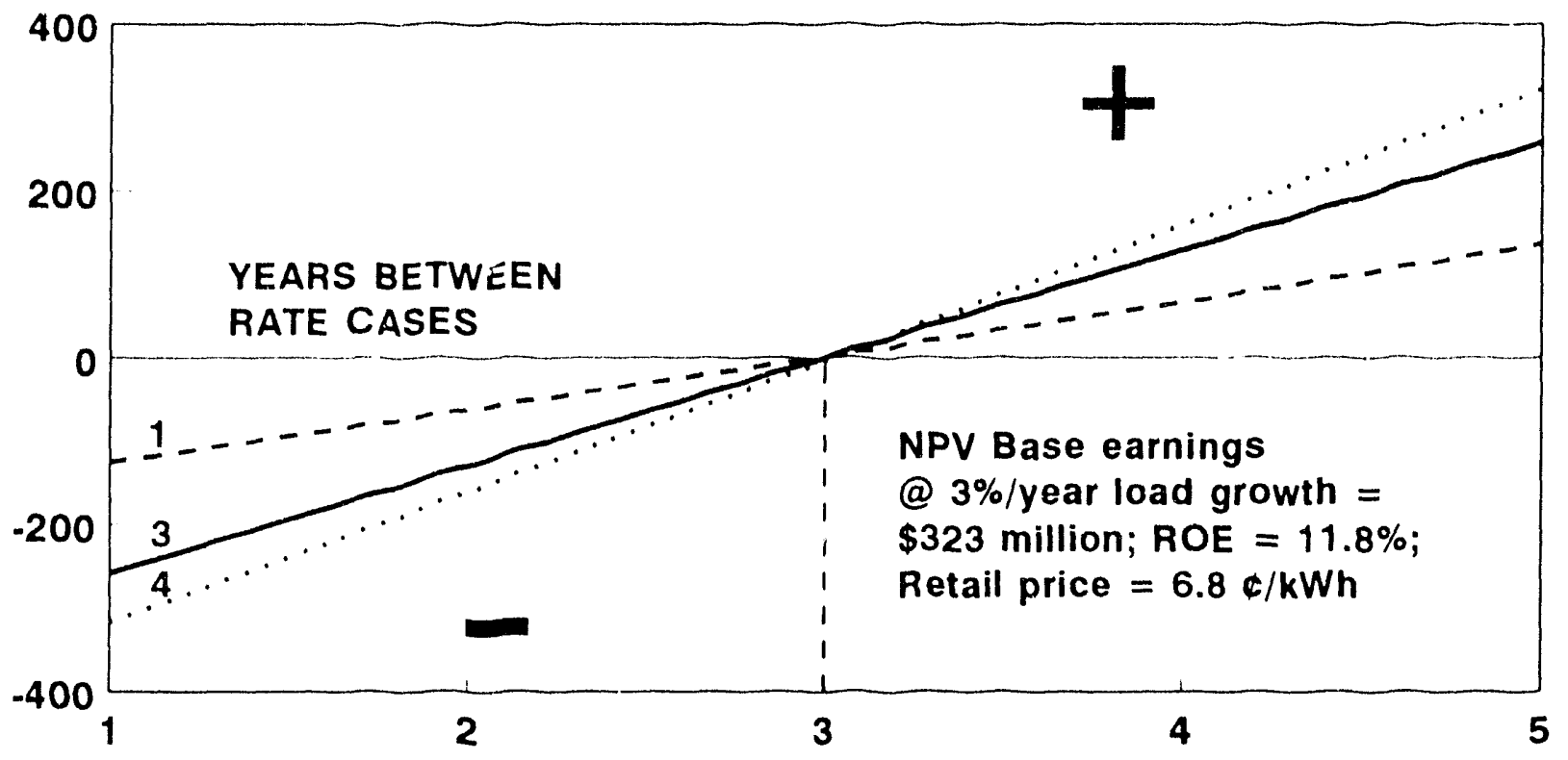

Fig. 1. The effects on PacifiCorp shareholder earnings of variations in load growth and the number of years between rate cases. (NPV is net present value, and ROE is return on equity.)

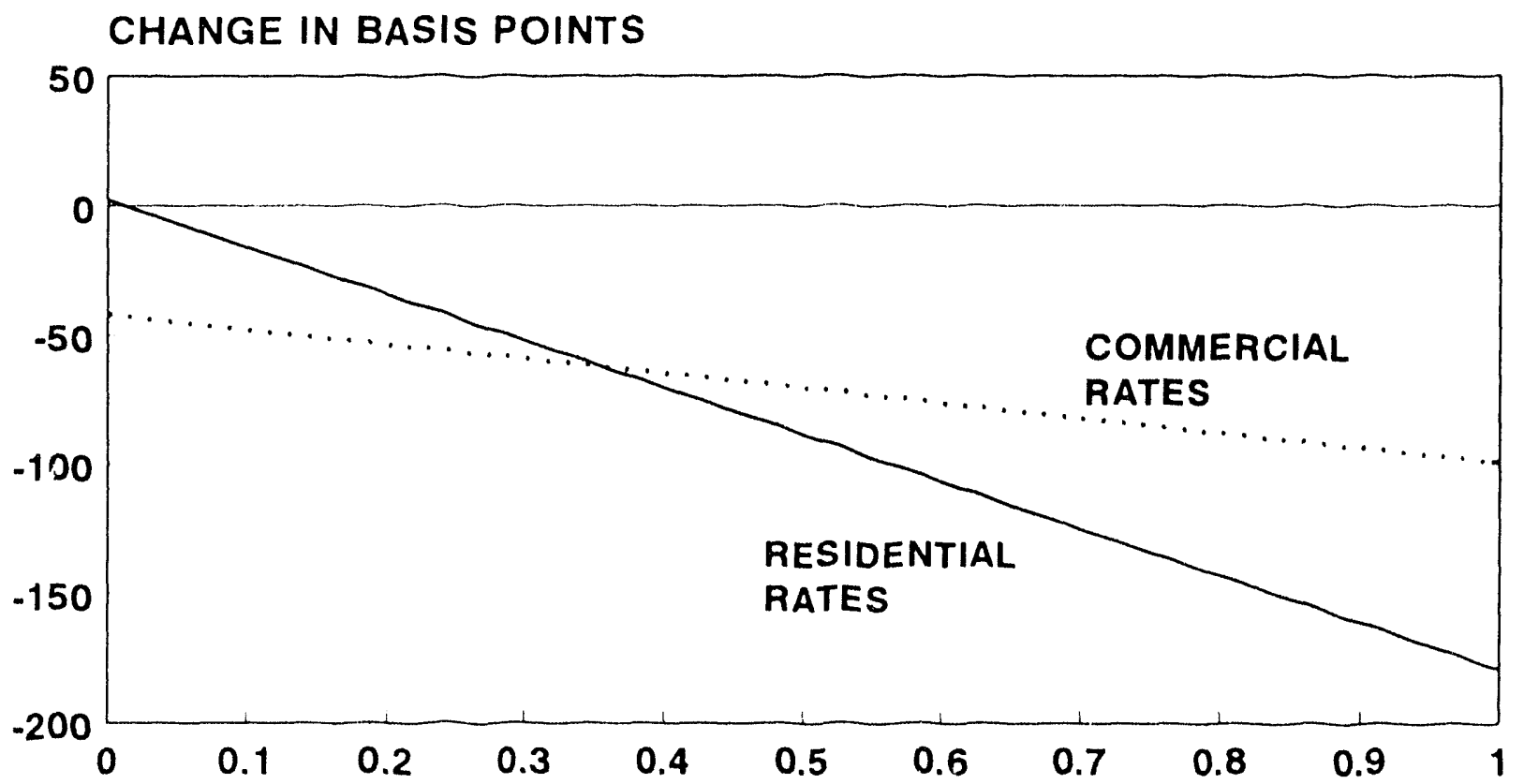

Fig. 2. The effects on PacifiCorp shareholder earnings of three-year DSM programs, as functions of conservation load factor and retail-price structure. 


\section{SOLUTIONS TO THE NET-LOST-REVENUE PROBLEM}

Commissions and utilities can choose among several mechanisms to address the problems discussed and quantified in the preceding chapter. The mechanisms include traditional command-and-control regulition, frequent rate cases, different retail rate tariffs, net-lost-revenue adjustments (NLRAs), or deccupling of electric revenues from sales. Decoupling mechanisms, of necessity, recouple revenues to something other than sales. Such recoupling mechanisms include explicit attrition adjustments intended to track the doterminants of tived costs, the number of urility customers, or the determinants of electricity sales. Some mechanisms that deal with the DSM-induced revenue loss include combinations of these approaches.

\section{COMMAND-AND-CONTROL REGULATION}

In this approach, the PUC specifies clearly what the utility should do. The commission then closely monitors subseguent utility actions for compliance with the PUC directive. If the utility does not follow the PUC order adequately, the commission can penalize the company in subsequent proceedings.

This approach works well in only one state, Wisconsin (Newman, Kihm, and Schoengold 1992). Wisconsin, however, is unique because it has annual rate cases and a future test year. Also, the Wisconsin Public Service Commission staff works closely on a dayto-day basis with the state's regulated utilities.

I know of no evidence to show that the command and control approach, by itself, has worked anywhere else in the U.S. To the contrary, the emphasis in recent years on removing the financial disincentives to DSM and providing incentives to utilities that run exemplary DSM programs suggests just the opposite (Nidel, Reid, and Wolcott 1992). Experience with incentives and decoupling in New York, California, and Washington show how these regulatory reforms can dramatically and rapidly change the strength and scope of utility DSM programs (Swanson 1992).

The Vermont Public Service Board (1990) recngnized the difficuity in ordering a utility to take actions inconsistent with the welfare of its shareholders:

Any effort to implement least-cost utility planking must recognize that implementation of demand-side measures requires a workable partnership between the litilities and their customers, supported by the regulatory framework within which they operate. To maxinize tineir effectiveness, 
demand-side programs must be carefully crafted, creatively marketed, and intelligently monitored. These characteristics cannot be achieved by regulatory fiat alone, and are not likely to be achieved at all if utilities are financially penalized for succeeding in lowering their sales.

Finally, the Colorado PUC (1993) stated clearly that it wanted to adopt a different approach:

One solution to this problem [financial incentives that inhibit utilities from pursuing DSM] would be increased oversight with greater reliance on command and control regulation. Given the limited resources available to monitor utility behavior in Colorado, as well as our preference to adopt a solution that positively reinforces the desired utility behavior without the imposition of constant regulatory oversight, this commission prefers to address the problem through regulatory reform.

\section{FREQUENT RATE CASES}

Annual rate cases, as shown in Fig. 1, greatly reduce - but do not eliminate - the utility's incentive to boost sales growth. Utilities in Wisconsin file annual rate cases with the Wisconsin Public Service Commission, and New England Electric files annual rate cases with the Federal Energy Regulatory Commission. However, rate cases are expensive, time consuming, and burdensome on all those involved. Therefore, PUCs and utilities may prefer to increase the time between rate cases rather than conduct rate cases more often. Also, frequent rate cases dampen the cost-cutting incentives that utilities face between rate cases.

\section{ALTERNATIVE RATE DESIGNS}

A PUC, in principle, could set retail rates for energy and demand exactly equal to utility short-run energy and demand costs. With such rates in place, utilities would face no shareholder incentive to boost electricity sales and no disincentive to run DSM programs that reduce sales.

To ensure that utilities collected enough revenue to cover allowed costs, the monthly customer charges would have to be increased greatly to compensate for the much lower energy and demand charges. However, as noted by the Connecticut Department of Public Utility Control (1991), "the dramatic increases in charges that are unrelated to the amount of consumption would be perceived by most customers as unfair, unjustified, and intolerable."

Most important, setting prices at short-run costs sends customers economically inappropriate signals that could lead to inefficient increases in electricity use. Thus, this 
option conflicts dramatically with the concept of economic efficiency, for which prices should reflect long-run marginal costs.

\section{NET-LOST-REVENUE-ADJUSTMENT MECHANISMS}

NLRAs are designed to compensate utilities for changes in revenues associated with utility DSM programs. As such, they are more sharply focused than mechanisms that break the link between sales and revenues (discussed below). NLRAs have been approved in 16 locations, including Arizona, Connecticut, the District of Columbia, Hawaii, Indiana, Iowa, Maryland, Massachusetts, Minnesota, New Hampshire, New Jersey, New York, North Carolina, Ohio, Oregon, and Vermont (Reid, Brown, and Deem 1993).

To implement an NLRA, the utility would first estimate the energy and load reductions caused by each of its past and present DSM programs for the year in question. These GWh- and MW-saving numbers are then multiplied by the difference between the retail price for each rate class and the short-term costs (both energy and capacity). The two products (lost energy and lost capacity revenue) are added together, again for each rate class. This sum is the net lost revenues caused by the utility's DSM program. It is called "net" because it is equal to the difference between the reduction in utility revenue minus the reduction in utility short-term costs (fuel costs plus variable operarion and maintenance costs).

NLRAs address only the lost revenue associated with a utility's DSM programs. The narrow focus of this mechanism excludes other factors that affect utility sales, revenues, and earnings. For example, the utility could simultaneously operate energy-efficiency and loadbuilding programs. Its NLRA mechanism would compensate it for lost revenues caused by the efficiency program, and the extra sales caused by the load-building program would benefit shareholders, leading to "dueling incentives." Thus, an NLRA would not eliminate utility incentives to operate load-building programs. In addition, an NLRA would, in principle, encourage utilities to operate DSM programs that look good on paper and would qualify for the NLRA, but would fail to produce energy savings in practice (Moskovitz, Harrington, and Austin 1992).

NLRAs could be controversial and difficult to administer (Swanson 1992). In particular, the estimated revenue losses from energy-efficiency programs could be reduced by the revenue gains from (1) utility promotional efforts and (2) increased off-system sales of electricity not captured in the FAC. Calculating the effects of load-building programs (i.e., both direct promotional programs and rate incentives) is likely to be as difficult as estimating the energy-saving effects of energy-efficiency programs. Similarly, estimating the amount and value of wholesale sales attributable directly to the electricity freed up by energy-efficiency programs is likely to be difficult.

In addition, estimating the lost revenue associated directly with the energy-efficiency programs may be difficult and contentious. Arguments might occur over the hours of 
operation for the lighting fixtures treated in a utility's DSM program, the number of years the measures are expected to remain in place and operate as expected, and the number of participating customers who are free riders and would have installed the utility-sponsored measures without the program. For a DSM program aimed at industrial customers, arguments might occur over the effects of the DSM measures on increased productivity and output, and therefore increased electricity use. These technical issues are difficult to resolve and could take up a great deal of time for PUC staff and commissioners.

Thu;, NLRA mechanisms place a substantial burden on program evaluation (Cummings 1992 and Hirst 1992). Evaluation results form the basis for the utility's claim that it is entitled to compensation for its net lost revenues. These results serve as documentation for the energy savings and load reductions contributed by the utility's DSM programs. Unfortunately, the state of the practice of DSM evaluation is such that precise estimates of program effects cannot be developed unambiguously.

Uncertainty in the estimates of program effects is also a problem in determining DSM-program cost recovery, in establishing an appropriate incentive to the utility for its DSM programs, and in resource planning, but the amount of money at stake is typically much higher for net lost revenues than for these other issues. The problem is compounded by an NLRA's need to identify energy and demand savings in detail - by rate class and rate block - to determine the amounts of revenue actually lost year after year.

Discussions with utility and PUC staff in Connecticut (Townsley 1993 and Quinlan 1993) and in Maryland (Switzer 1993 and Tighe 1993) suggest that these problems can be overcome. Although the experience with NLRAs is limited (generally less than a year) in both states, both the utility and PUC people were positive about the experiences to date. In both states, the active presence of a DSM collaborative made it much easier than it otherwise would have been to establish the protocols to calculate energy and demand savings for each DSM program. Outside the hearing room, the collaborative participants were able to agree on the methods to use and the estimates to apply for each program.

In addition, both utilities (Baltimore Gas \& Electric and Northeast Utilities) made substantial commitments to evaluating their DSM programs. The results of these evaluations will be used, in later years, to adjust the NLRA methods and assumptions.

Woolf (1993), in his review of the operation of NLRAs, reached similar conclusions. He found that NLRAs work without controversy where there is substantial cooperation between the utility and other parties (e.g., through a DSM collaborative), where the utility is doing competent evaluations of its DSM programs, where the IRP process is working well, and where the utility is acquiring cost-effective DSM resources. Woolf notes that "measurement issues, while cumbersome, can be resolved through agrcements between interested parties, and they will become less important over time as better monitoring and evaluation practices are applied." 
Utility experience in, and competence with, evaluation is growing rapidly in many parts of the country. In addition, some regulatory agencies are adopting protocols for utilities to use ir estimating the energy and load reductions caused by their DSM programs. For example, the U.S. Environmental Protection Agency (1993) recently published its Conservation Verification Protocols, which it will use in reviewing applications for the sulfur allowances in the Conservation and Renewable Energy Reserve. Similar protocols were developed in New Jersey and in California.

An NLRA mechanism can work satisfactorily only for programs that produce "tangible" and easily measured energy and load reductions. However, programs aimed at educating the public; training installers and technicians; and promoting stricter efficiency standards for new construction, appliances, and equipment are very hard to measure. But, these "soft" programs might also be cost effective. Adopting a mechanism that rewards a utility only for "hard" DSM might be counterproductive, leading to a component approach to DSM programs rather than a comprehensive and integrated approach.

Overall, NLRAs are probably best suited for utilities that have in place an effective IRP process, are committed to acquiring cost-effective DSM resources as part of their IRP, are part of a well-functioning and ongoing DSM collaborative, and are committed to conducting competent evaluations of their DSM programs. NLRAs can work best if the PUC staff provides substantial oversight of utility programs. By devoting resources to DSMprogram evaluation and review of programs for load-building activities, the incentive to build uneconomic load that remains with an NLRA may be overcome. To some extent, the collaboratives in Connecticut and Maryland serve this function.

\section{DECOUPLING}

Decoupling is a two-part mechanism. The first part breaks the link between utility revenues and $\mathrm{kWh}$ sales. The second, more difficult part involves "recoupling" revenues to something else, such as growth in the number of customers, the determinants of changes in fixed costs, or other factors. Decoupling generally follows one of two paths. It tracks either fixed costs or actual revenues. Decoupling operates in four states, California, Washington, New York, and Maine, and is being considered in several other states.

\section{California and New York}

California was the first state, in 1981, to implement a decoupling system, called the Electric Revenue Adjustment Mechanism (ERAM) (Marnay and Comnes 1990 and 1992). Once every three years, the California PUC sets rates for each of the state's utilities following much the same procedures used in states witiout decoupling. The rate-case process, based on a future test year, includes a determination of the amount of money the utility can recover for its fixed costs. The ERAM account is used to ensure that, for each of the years between general rate cases, the utility collects no more and no less than the authorized amount for nonfuel costs. As discussed below, attrition mechanisms are used to 
adjust this amount for each year to reflect changes in the determinants of the utility's fixed costs.

During each of the three years between rate cases, the utility collects in a balancing account any excess revenues associated with sales higher than those included in the test year (or deficit revenues associated with sales below those in the test year). During the following year, these excess (deficit) revenues are refunded to (collected from) customers by decreasing (increasing) the price of electricity. These revenue adjustments deal only with fixed costs; ERAM does not address changes in variable costs, which are handled through a FAC.

In addition to ERAM, allowed fixed costs are adjusted each year through an attrition adjustment (Ziering 1986). This mechanism adjusts the components of fixed costs on the basis of various factors that are not controlled by the utility, such as inflation rates and other cost and productivity indices.

Attrition in California includes three components: financial, operational, and rate-base attrition. Financial attrition adjusts for changes in the utility's cost of capital. These adjustments are handled in an annual proceeding that covers all the California energy utilities. These proceedings set interest costs and return on equity, based primarily on actual bond interest rates.

Operational attrition adjusts for changes in operating costs, such as wage rates and the costs of certain materials. These costs are changed on the basis of price indexes that are specified in the general rate cases. No adjustments are made for changes in the number of employees or the quantities of materials used. Presumably, these cost increases are offset by productivity gains. Operational attrition protects utility shareholders from the risks of inflation while preserving the cost-minimization incentives inherent in traditional ratemaking.

Rate-base attrition adjusts for changes in the utility's ratebase. These adjustments are based primarily on forecasts of capital expenditures developed during the general rate case.

Thus, while ERAM breaks the link between revenues and sales, the attrition mechanisms recouple revenues to the determinants of changes in fixed costs. Because the attrition mechanisms are based primarily on cost indexes, not the utility's actual costs, utility productivity improvements and cost-cutting measures benefit utility shareholders until the next rate case.

In practice, California's mechanism is a tradeoff between frequent, small rate changes and less frequent, larger rate changes. Overall, ERAM and attrition should have little effect on the amount of money a utility collects from its customers. Figure 3 shows the effects of these mechanisms on retail electricity prices for California's two largest utilities, Pacific Gas 
and Electric (Smith 1992) and Southern California Edison (Lisbin 1993)." For the ten-year period from 1982 through 1991, PG\&E's retail customers experienced six price increases and four price decreases. The largest changes were $-3.5 \%$ (1987) and $+4.5 \%$ (1989). Over the coulse of the decade, customers faced a total price increase of $9 \%$.

\section{\% PRICE CHANGE CAUSED BY ERAM}

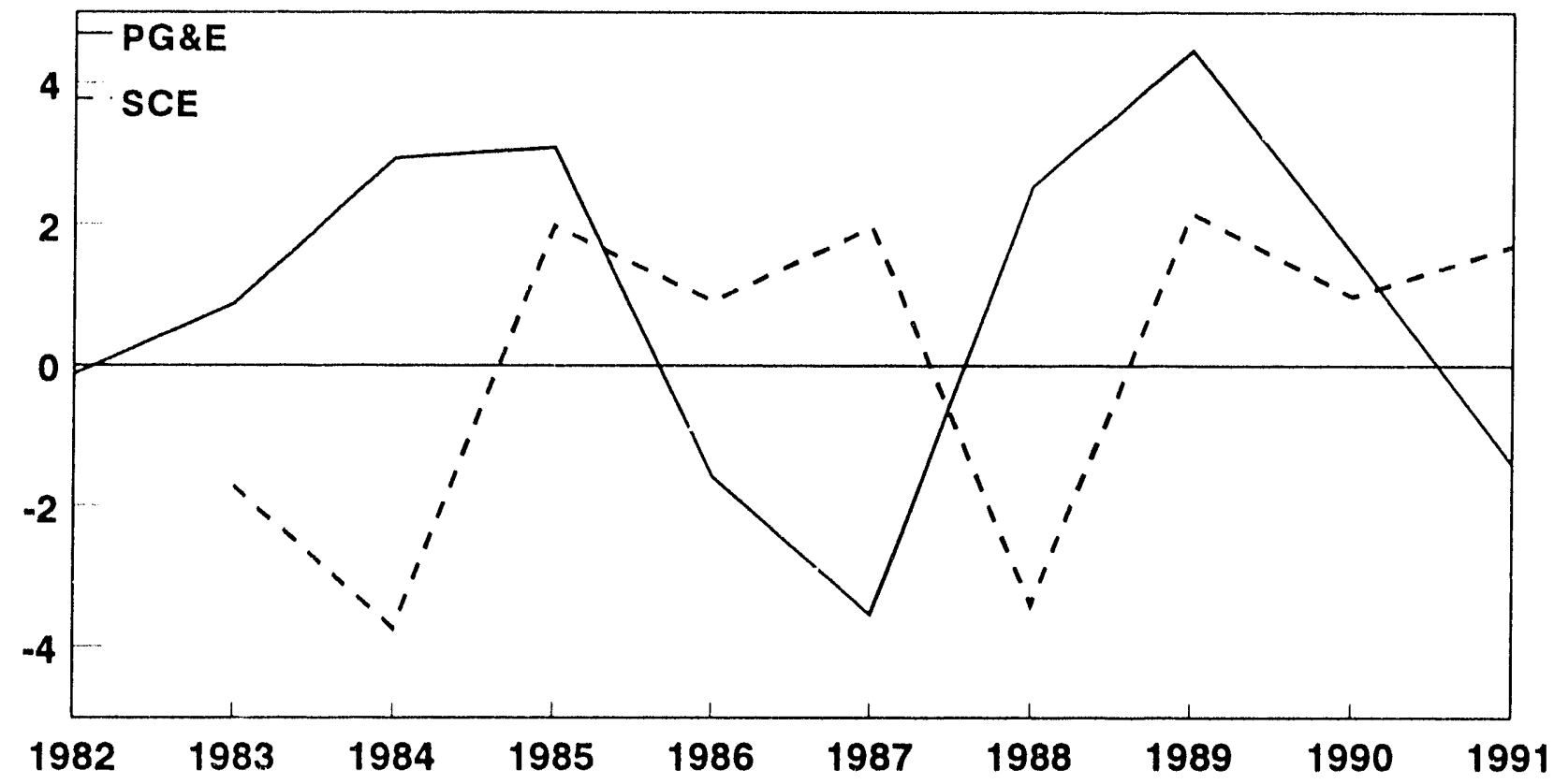

Fig. 3. The percentage changes in retail electricity prices caud by ERAM and attrition for Pacific Gas and Electric and Southern California Edison.

SCE's customers faced six price increases and three price decreases from 1983 to 1991. The largest changes were $-3.7 \%$ in 1984 and $-3.4 \%$ in 1988 . During this nine-year period, SCE's customers faced a total price increase of less than $1 \%$.

These results show that the amounts of money flowing through the ERAM accounts are small. It is important to note that ERAM and attrition affect primarily the timing of price changes, rather than the amounts of price changes. That is, the factors that affect utility costs would be treated in the three-year general rate cases, if they were not already included in ERAM and attrition.

The New York decoupling mechanisms, including the three-year rate-case cycle, are similar to the ones used in California.

*Eto, Stoft, and Belden (1993) provide additional details on the historic impacts of ERAM in California. They show that ERAM "has had a negligible effect on rate levels and has, for PG\&E, actually reduced rate volatility." 
Washington and Maine

Decoupling mechanisms were adopted in Washington and Maine in spring 1991; see, for example, Washington Utilities and Transportation Commission (1991). In these two states, electric revenues are decoupled from sales, as in California. But these states do not use an explicit attrition mechanism to adjust for increases in fixed costs over time. Instead, to cover increases in fixed costs, these two PUCs recoupled revenues to growth in the number of electricity customers.

Recent orders from the Washington and Maine commissions point to some problems with revenue-per-customer (RPC) decoupling related to price volatility. The Washington Utilities and Transportation Commission (1992) expressed considerable concern about the large amounts of money flowing through Puget Power's Periodic Rate Adjustment Mechanism (PRAM). In September 1991, the Commission granted a PRAM rate increase of $\$ 28$ million and in September 1992 approved another $\$ 66$ million increase. These dollar amounts are equivalent to rate increases of about $3 \%$ and $7 \%$. The Commission noted that "unusually warm weather [which reduced electricity consumption and the amount of low-cost hydropower] and other circumstances worked to cieate an unusually large deferred amount." Indeed, as Fig. 4 shows, more than half of these price increases were caused by changes in power-supply costs (replacements for the low-cost hydro and new purchased-power contracts). Puget Power does not have a FAC. It flows purchased-power costs through its PRAM, which includes a decoupling component.

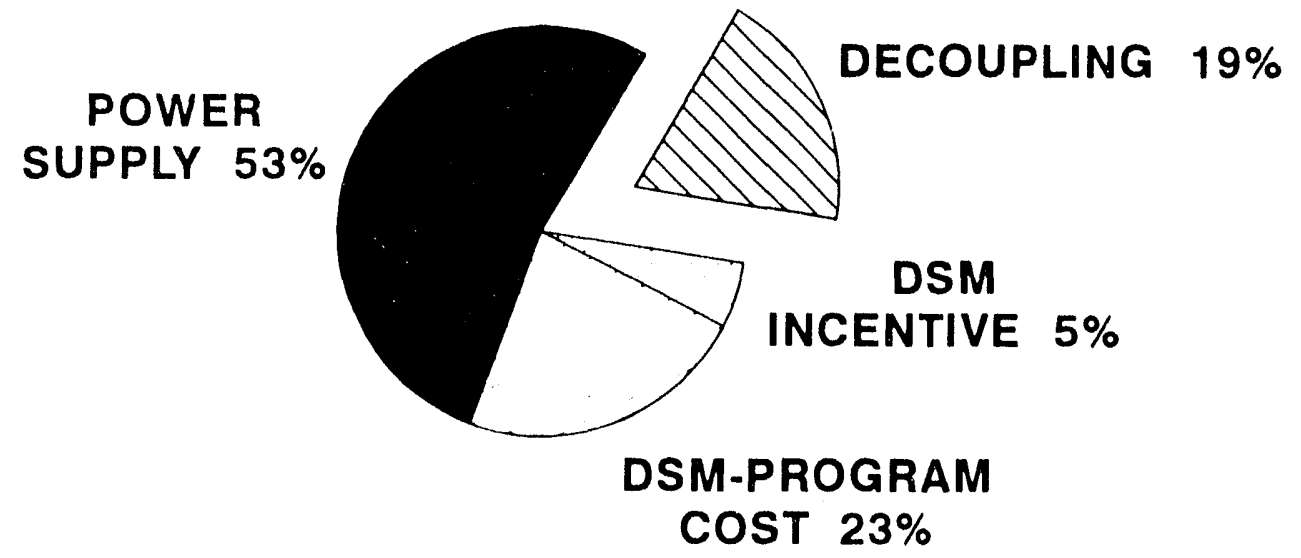

Fig. 4. Factors accounting for electricity-price increases in Puget Power's PRAM. 
The Washington experience suggests that it might be a mistake to use a decoupling mechanism to collect other costs (i.e., power-supply costs). In Puget Power's case, these other costs, not decoupling itself, led to large price increases.

Since the Commission issued its order in September 1992, Puget Power has filed a rate case; after hearings on that rate case, the Commission will decide whether to continue the decoupling mechanism. The Commissioners have made statements since issuing their September 1992 order showing their interest in continuing the decoupling experiment. In addition, Puget Power's CEO filed testimony (Sonstelie 1993) supporting continuation of decoupling:

The weather and hydro conditions which occurred during the PRAM 1 period - October 1991 through September 1992 - were far from average, and it would have been helpful to evaluate PRAM and decoupling on the hasis of a longer, and more representative, period.

[T] he PRAM/decoupling mechanism has performed well to date in meeting the Commission goals: ... Adjustment for Factors Beyond a Utility's Control ... Purchased Power Cost Recovery ... Conservation Cost Recovery ... [and] Incentives for Least Cost Planning.

[F]or Puget Power, the PRAM/decoupling mechanism was essential for us to triple the amount of conservation.

In response to a directive from the Commission, Puget Power proposed to modify its decoupling mechanism to extend the cost recovery period to two years. This change would reduce the rate swings that customers would otherwise experience. The Commission will issue its order later this year and decide, at that time, whether to continue, modify, replace, or abandon decoupling.

A month after the Washington commission issued its order, the Maine PUC (1992) expressed its concern about the effects of decoupling for Central Maine Power. Halfway through the three-year trial period, the amount accrued, almost $\$ 41$ million, represented a $5 \%$ rate increase (3.3\%/year increase). As in Washington, the increase was caused in part by nondecoupling factors. In particular, the prolonged Maine recession led to an overestimate of future load growth at the end of CMP's prior rate case. Specifically, while per-customer electricity use grew at almost 3\%/year between 1980 and 1988, it declined hy more than 1\%/year between 1988 and 1991. Rather than reopen the rate case, the par'ss agreed to stick with the prerecession forecast and let decoupling address the ensuing revenue shortfall.

In early 1993, several parties filded a settlement agreement with the Maine PUC. This agreement, accepted by the Commissichn, terminates the three-year decoupling experiment three months early. In its order, the Maine PUC (1993) noted that "a relatively small 
portion of these [decoupling] accruals was due to DSM efforts. The vast majority was because the recession had reduced sales."

In March 1993, as part of its general rate-case filing, CMP (1993) filed a report with the Commission on decoupling. CMP argued that its mechanism worked as intended and that it did "remove the immediate financial penalty of ongoing DSM programs." CMP suggested that the Commission keep RPC decoupling in place.

The company suggested a "few simple revisions" to its decoupling mechanism. These include use of a more accurate sales forecast, calculation of the allowed revenue-percustomer amount hased on projected customer counts, and the filing of a rate case if large accruals begin to occur.

Later testimony from other parties and the response from CMP seemed to abandon consideration of decoupling or other mechanisms to remove the disincentives to utility DSM programs. Instead, the parties focused on changing regulation to recognize the increasingly competitive environment in which CMP operates. Both the intervenors and CMP proposed various types of incentive regulation, including a cap on price increases and greater flexibility in pricing electricity.

As in Washington, the outcome will be known only when the Commission issues its order, later this year, in the current CMP rate case. However, decoupling may be dropped, primarily because none of the parties is supporting it.

\section{Other Proposals}

In response to an order from the Oregon PUC (1992), Portland General Electric (1993) and other parties developed a decoupling proposal that relies on frequent rate cases. The PGE proposal includes a two-year future test period for general rate cases. In such a rate case, the PUC would set retail load forecasts, revenues, and variable costs for each month during the next two years. Thus, the rate case would produce monthly values of the amounts of money PGE could collect for fixed-cost recovery.

Actual revenues, sales, and variable costs would be recomputed each month on the basis of differences between normal and actual weather. This step is intended to ensure that the utility (rather than customers) bear the price volatility associated with changes in weather.

Differences between the forecast margins computed during the rate case and the decoupling margins computed each month on the basis of actual sales and actual weather is called the decoupling adjustment. This adjustment would be cumulated over a six-month period, with the six-month balance refunded to (or collected from) retail customers during the following 18 months. To further limit the price volatility associated with this mechanism, these price changes are subject to a $\pm 3 \%$ rate cap. If the cap is binding, the period of collection is extended. 
Other utilities, including PacifiCorp (1993); Florida Power Corporation (1993); Potomac Electric Power; Montana Power; and groups in Colorado, Georgia, and Utah, are considering different mechanisms to break the link between electric revenues and sales. Potomac Electric Power (1993) proposed a simple ERAM, in which changes in the national Consumer Price Index are used to set the company's allowed revenues. The company found that its nonfuel costs are more closely correlated with the CPI than with the number of customers it serves. Montana Power (Corcoran 1993) proposed a decoupling system based on the difference between forecast retail electricity sales and actual weather-normalized sales.

\section{Risk Shifting}

Decoupling as implemented in California, New York, Washington, and Maine shift the revenue and price risks associated with changes in weather from utilities to customers. As illustrated in Oregon and Montana, however, risk shifting can be decided separately from the decision to decouple. Under traditional regulation, if electricity sales are higher because the summer is especiably hot (or the winter particularly cold), the utility keeps that extra revenue. With some decoupling mechanisms, however, the company would refund that revenue fo customers in the following year. On the other hand, if the weather is especially mild and electricity sales are low, the utility operating under these mechanisms will not collect enough revenues to meet its authorized revenues; it will therefore collect that deficit the following year. The same logic applies to higher (lower) sales caused by high (lower) economic growth.

RPC decoupling shifts only some of the risks associated with changes in economic growth to customers. The economy-related risks associated with changes in the number of customers remain with the utility.

Whether this shifting of risks is good or had depends on one's perspective. There is no fundamental reason why these risks should reside with either the utility or its customers. Consider the debates two decades ago over FACs. Before that time, utilities bore all the risks of fuel-price volatility. After the 1973 oil embargo, utilities argued, and PUCs generally agreed, that it was appropriate to let customers bear the risks of changes in fuel prices.

Also, while these decoupling mechanisms shift price risks from the utility 10 its customers, they reduce hill volatility for customers with weather-sensitive loads. Electricity bills are the product of prices and consumption. Under traditional regulation, if the winter is very cold, electricity use and bills are high, although prices remain unchanged. Under decoupling, electricity use will also he high, but prices the following year will be lower, and therefore bills (with a lag) will not increase as much as they would under traditional regulation.

Because some forms of decoupling shift the risks of changes in weather and economic: conditions from utilities to customers, electricity prices can be more volatile than under traditional regulation. One way to reduce the volatility of price changes is $t$ speread the 
decoupling-induced changes over more than one year. A two-year amortization period woulci reduce the year-to-year swings in electricity price.

Another way to reduce the volatility in electricity prices that decoupling might cause is to impose rate caps on the allowed price changes. To be fair, this limit would be imposed on both price increases and decreases (e.g., to limit price increases to no more than $3 \%$ and price decreases to no more than $-3 \%$ ). Although such price caps might partially recouple revenues to sales, they impose limits on how much prices can vary from year to year. Moskovitz, Harrington, and Austin (1993) discuss these and other ways to reduce the risk shifting associated with decoupling.

Finally, to the extent that risks are shifted to customers, utility revenues will be more stable. This greater stability should lower the utility's overall cost of capital, which in turn would lower electricity prices.

\section{Summary}

The recent experiences in Washington and Maine show that when adverse weather and/or a poor economy occur, price changes can be important. Even in those states, however, decoupling worked as intended. And the price increases that flowed through the decoupling mechanism might have occurred anyway (although with some delay) if the utilities, absent decoupling, had filed rate cases. Finally, when the economy is growing rapidly and/or the weather is favorable, decoupling will lead to price decreases (as shown by the record of ERAM-induced price changes in California).

In general, decoupling is likely to be most appropriate for commissions that want utilities to run ambitious DSM programs and for utilities that already run (or plan to run) large DSM programs. Decoupling also makes sense in states where the PUC has only limited staff resources to monitor the utility's DSM programs.

Decoupling removes both the incentive to increase electricity sales and the disincentive to run energy-efficiency programs. This situation occurs because, with decoupling, utility earnings are driven by authorized revenues rather than actual revenues. Unlike NLRAs, decoupling requires no estimates of the energy savings and load reductions caused by a utility's DSM programs. And decoupling is, at least in principle, simple to administer.

RPC decoupling, although much simpler than the attrition mechanisms used in California and New York, has two potential problems. First, for utilities with increases in electricity use per customer, some adjustment must be made to allow revenues to grow more rapidly than would occur with simple RPC decoupling. Considerable disagreement might arise about how to compute that growth factor because its value would affect utility revenues. 
Second, large industrial customers impose costs on utilities that are much larger than the average amount recovered through the decoupling mechanism. Therefore, some of these customers are concerned that utilities with RPC decoupling might discriminate against them. Implementing RPC decoupling separately for each customer class largely addresses this issue.

These concerns with decoupling led to the development of statistical recoupling, which is discussed in the next four chapters. 


\section{STATISTICAL RECOUPLING CONCEPTS}

I developed a new mechod called statistical recoupling. This decoupling approach should interest utilities and commissions that do not want to adopt an attrition mechanism (in which allowed revenues are tied to the determinants of fixed costs) and that are concerned about the decoupling-induced changes in electricity prices that have occurred in recent years. This new mechanism minimizes changes from current rate making while severing the link between sales and revenues. One way to accomplish these goals is to let the utility retain the risks associated with fluctuations in the weather, the local economy, and customer growth, as it does under current regulation.

Like other decoupling mechanisms, SR involves two steps. The first step decouples revenues from electricity sales. In the second step, revenues are recoupled to statistical estimates of electricity use.

Implementing an SR mechanism requires the use of statistical models that explain well the effects of weather and economic activity on electricity sales. Such a system might be developed as follows. The utility would statistically analyze historical data (e.g., for the past 10 to 15 years) on quarterly or monthly electricity sales as a function of weather severity (e.g., heating and cooling degree days), service-area economic activity (e.g., income or employment), retail electricity prices, and other factors that materially affected electricity sales. This model would be estimated either separately for each customer class or for all retaii sa.es in aggregate. For example, the model might have the following form:

$$
E_{i 1}=a_{i}+b_{i}^{*} D D_{1}+c_{i} * Y_{1}+d_{i}^{*} P_{1}+e_{i}^{*} C_{1}+\ldots,
$$

where

E is electricity use $(G W h)$ for month or quarter $t$ and customer class $i$;

DD is a measure of weather severity (such as heating or cooling degree days);

$\mathrm{Y}$ is a measure of economic activity;

$P$ is retail electricity price;

$\mathrm{C}$ is the number of utility customers;

... represents other factors that affect electricity use; and 
$a, b, c, d$, and e are coefficients that are statistically determined from historical data.

The coefficients from this statistical model would then be used to estimate electricity use for each future year, given the actual weather patterns, economic conditions, and electricity prices for that year. For example, the utility might use data from 1975 to 1991 to create this model. The model would then be used to calculate electricity use for the year 1993, based on actual weather, economic conditions, and electricity prices for 1993. The utility's allowed revenue in 1993 would then be the product of the computed electricity use $\left(E^{\prime}\right)$ and the "fixed" price of electricity $\left(P_{f}\right)$ summed over all the retail customer classes i:

$$
\text { Allowed revenues }_{1993}=\underset{\mathrm{i}}{\sum}\left(\mathrm{E}_{\mathrm{i}, 1993}^{\prime} * \mathrm{P}_{\mathrm{f} \mathrm{i}, 1993}\right) \text {. }
$$

The difference between actual 1993 electric revenues and the allowed revenues is the amount of money flowing through the utility's recoupling account:

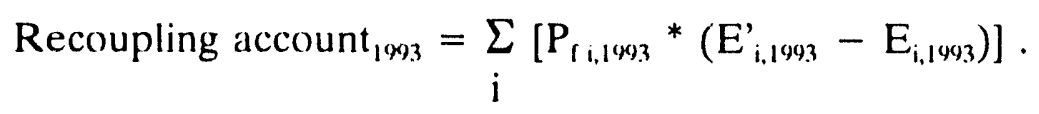

$\mathrm{P}_{\mathrm{f}}$ is the fixed-cost component of retail electricity prices. It is lower than the average retail electricity price for two reasons. First, it is adjusted down to remove the amount of revenue collected through the monthly customer charge. Second, it is adjusted down to reflect the base energy cost $\left(\mathrm{P}_{v}\right.$, either the variable cost allowed in the utility's current FAC or, for utilities without a FAC, the actual variable cost for that year). "That is:

$$
P_{f}=\frac{\text { Retail revenue }- \text { Revenue from customer charges }}{\text { Retail sales }}-P_{v}
$$

Typically, $\mathrm{P}_{\mathrm{f}}$ is 50 to $75 \%$ of the average retail electricity price.

If the recoupling account is positive (i.e., the utility was authorized to collect more money than it did), it will raise the price of electricity the next year to recover this difference. Of course, if the recoupling account is negative, the price will be reduced during the following year.

While the models used in SR are virtually identical to those used by utilities, the application is quite different. Utilities routinely estimate the effects of weather, the economy, and other factors on electricity sales as part of their short- and long-term forecasting efforts.

When utilities use their models to forecast electricity sales, they must make assumptions about the values for the explanatory variables. For example, a utility in 1993

\footnotetext{
" $P_{v}$ must be calculated at the customer meter (and not at the power plant busbar) to appropriately account for line losses. Its calculation depends on the particular FAC, if any, used by the utility.
} 
wanting to forecast sales for 1994 and 1995 will have to assume values for income, number of customers, and other factors for these two future years. However, in SR, these models are used to determine allowed sales for the most recent year. And values for all the explatiatory variables are available at that time. In other words, SR involves no assumptions on what the values will be for heating degree days, income, electricity price, and so on.

With respect to allocation of risks between a utility and its customers, statistical recoupling is like existing regulation. The utility, under $S R$, retains the risks associated with changes in sales and revenues caused by changes in all the variables included in the SR model. For example, if the model includes heating degree days as an explanatory variable, then the company's allowed revenues will change according to changes in actual heating degree days. If the winter is especially mild, the value for heating degree days will be lower than normal. This lower value will then, through the SR model, cut allowed revenues. Unlike other decoupling approaches, this one adjusts the revenues for fixed-cost recovery to vary with changes in the weather, local economy, and any other factors explicitly included in the models. This conclusion assumes that the statistical model(s) will accurately capture the effects of changes in weather, the economy, and electricity price on electricity use. 


\section{STATISTICAL RECOUPLING MODELS}

\section{DATA}

I obtained data from five utilities to use in testing statistical recoupling (Table 2). Two of the utilities provided monthly data (New England Electric System's Massachusetts Electric Company subsidiary and Nevada Power Company), while the other three provided quarterly data (PacifiCorp's Utah service area, Public Service Company of Colorado, and Southern California Edison). All five utilities provided 13 or more years of data for their residential, commer cial, and industrial customer classes. The utilities also provided data on heating and cooling degree days, average electricity prices for each customer class, and various measures of economic activity in their service areas. The price variable used in all these SR models is the ratio of revenues to sales; it does not explicitly treat the tariff details (i.e., monthly customer charge, energy charges, and demand charges).

\section{MODEL RESULTS}

In developing SR models, I emphasized simplicity rather than accuracy. So, I estimated only linear models (i.e., I ignored the possibility that log-log or log-linear models might perform better) and I used the minimum number of variables that seemed reasonable." In particular, I used no binary (dummy) variables, as did the five utilities in their estimation of statistical models. For example, Nevada Power used binary variables for each month in combination with the cooling degree day variable to allow for differences in the amounts of electricity used for air conditioning by month. Other utilities used binary variables to reflect unusual weather or economic conditions (e.g., a strike). Finally, I used no lagged dependent variables (e.g., last quarter's electricity use) as explanatory variables; to do so would recouple revenues to sales.

To begin, I used the data from PSCo to construct two sets of statistical models. ${ }^{*}$ One set dealt with each customer class separately, while the second set dealt with total sales. In each case, I used the data through 1989 to estimate the statistical models. I then used the last three years (1990, 1991, and 1992) to see how well the models performed.

The models include terms that correct for autocorrelation, a common problem with time-series models. Autocorrelation refers to correlations among the error terms in a statistical model. Failure to correct for autocorrelation leads to higher standard errors for the model coefficients.

\#I used Forecast Pro for DOS to estimate the models presented here (Stellwagen and Goodrich 1993). 
Table 2. Customer classes and data from five utilities

\begin{tabular}{|c|c|}
\hline Customer classes & Independent variables ${ }^{a}$ \\
\hline $\begin{array}{l}\text { Nevada Power (monthly data, 1981-1992): } \\
\text { residential, general service, large general } \\
\text { service, hotel }\end{array}$ & Fraction of apartments in Clark County \\
\hline $\begin{array}{l}\text { New England Electric (monthly data, } \\
\text { 1980-1992): residential electric heat, } \\
\text { nonelectric heat, master-metered; } \\
\text { commercial; industrial }\end{array}$ & $\begin{array}{l}\text { Disposable income, personal income, } \\
\text { employment (nonmanufacturing and } \\
\text { manufacturing), wholesale production } \\
\text { index }\end{array}$ \\
\hline $\begin{array}{l}\text { PacifiCorp - Utah (quarterly data, 1978- } \\
\text { 1992): residential, commercial, all } \\
\text { industrial, four largest industrial customers }\end{array}$ & $\begin{array}{l}\text { Income, employment (manufacturing, } \\
\text { mining, total), industrial output }\end{array}$ \\
\hline $\begin{array}{l}\text { Public Service Company of Colorado } \\
\text { (quarterly data, 1970-1992): residential, } \\
\text { commercial, industrial }\end{array}$ & Income, employment \\
\hline $\begin{array}{l}\text { Southern California Edison (quarterly } \\
\text { data, 1980-1992): residential, commercial, } \\
\text { industrial }\end{array}$ & $\begin{array}{l}\text { Income, employment (manufacturing and } \\
\text { nonmanufacturing), unemployment rate, } \\
\text { gross state product }\end{array}$ \\
\hline
\end{tabular}

${ }^{a}$ All the utilities sent data on electricity sales, number of customers, revenues, and price for each customer class, as well as data on heating and cooling degree days.

Sources: Farina (1993), Southern California Edison (1993), Tamashiro (1993), Wharton (1993), and Wordley (1993).

I used two criteria to assess the feasibility of applying SR to PSCo. First, I looked at the statistical properties of the model to see how well it did in simulating the past. Second, I looked at the changes in electricity prices that SR would have caused for the last three years (1990 through 1992).

The class-specific models had good statistical properties. The models all explained $93 \%$ or more of the quarterly variation in electricity use for each customer class. (Such high values for $\mathrm{R}^{2}$ are typical of time-series models.) In addition, the coefficients of each variable always had the expected sign. As examples, the coefficients for heating and cooling degree days were both positive, and the coefficient for electricity price was negative. The coefficients for heating and cooling degree days were statistically significant at the $99 \%$ level, while the coefficients for electricity price and income were often significant at only the 80 to $90 \%$ level. 
In terms (ri their ability to simulate correctly electricity use for 1990, 1991, and 1992 the models' periormances were also good. The residential model had errors of $-1.5,-2.4$, and $-2.8 \%$ for these three years. The commercial model had errors of $-1.6,-3.1$, and $-2.5 \%$. And the industrial model had errors of $+1.3,+2.2$, and $+1.8 \%$. The combined effect of these simulations, when weighted by the contribution of each sector to total retail revenues, was quite good. As shown in the top part of Table 3, the three models together had combined errors of $-1.2 \%,-2.2 \%$, and $-2.1 \%$ for 199()$, 1991$, and 1992 .

The aggregate model of total electricity use combines data from the residential, commercial, and industrial sectors. Thus, electricity use and the number of customers represent the totals across the three sectors, and electricity price is the ratio of total revenues to total sales across the three sectors. This model had much better statistical properties and an even more accurate simulation record than did the three sector-specific models (Fig. 5). This model had errors of $-0.5 \%, 0.0 \%$, and $+1.1 \%$ for the three years. And the aggregate model of total electricity use per customer had errors of $+0.2 \%,+1.4 \%$, and $+0.8 \%$ for 1990,1991 , and 1992. The aggregate model of electricity use is the simplest, has the best statistical properties, and yields the smallest errors. For the three years 199() through 1992, SR based on this model had an average error of only $(1.2 \% / y e a r$. If statistical recoupling had been in place in Colorado, it would have led to a $0.3 \%$ price decrease in 199() , no price change in 1991 , and a $0.6 \%$ price increase in 1992 .

I developed similar statistical models with the data from the other four utilities; the results are similar to the PSCo results. For example, I conducted the same type of analysis described above with monthly data from Nevada Power (bottom part of Table 3). The combined results, across the three primary customer classes, had errors slightly larger than those obtained with the PSCo models. The aggregate models had smaller errors than the combination of class models, consistent with the PSCo results.

Table 3. Percentage error in PSCo and NPC retail electricity sales had statistical recoupling been used in 199(), 1991, and 1992

\begin{tabular}{lccc}
\hline $\begin{array}{c}\text { Combination of } \\
\text { class models }\end{array}$ & $\begin{array}{l}\text { Total } \\
\text { sales }\end{array}$ & $\begin{array}{c}\text { Total sales } \\
\text { per customer }\end{array}$ \\
\hline 1990 & Public Service Company of Colorado & \\
1991 & -1.2 & -0.5 & $+(1.2$ \\
1992 & -2.2 & 0.0 & +1.4 \\
& -2.1 & +1.1 & +0.8 \\
1990 & & & \\
1991 & Nevida Power Company & -1.9 \\
1992 & -1.8 & -1.8 & $-(0.7$ \\
\hline
\end{tabular}


\% ERRORS IN ELECTRICITY SALES AND PRICE

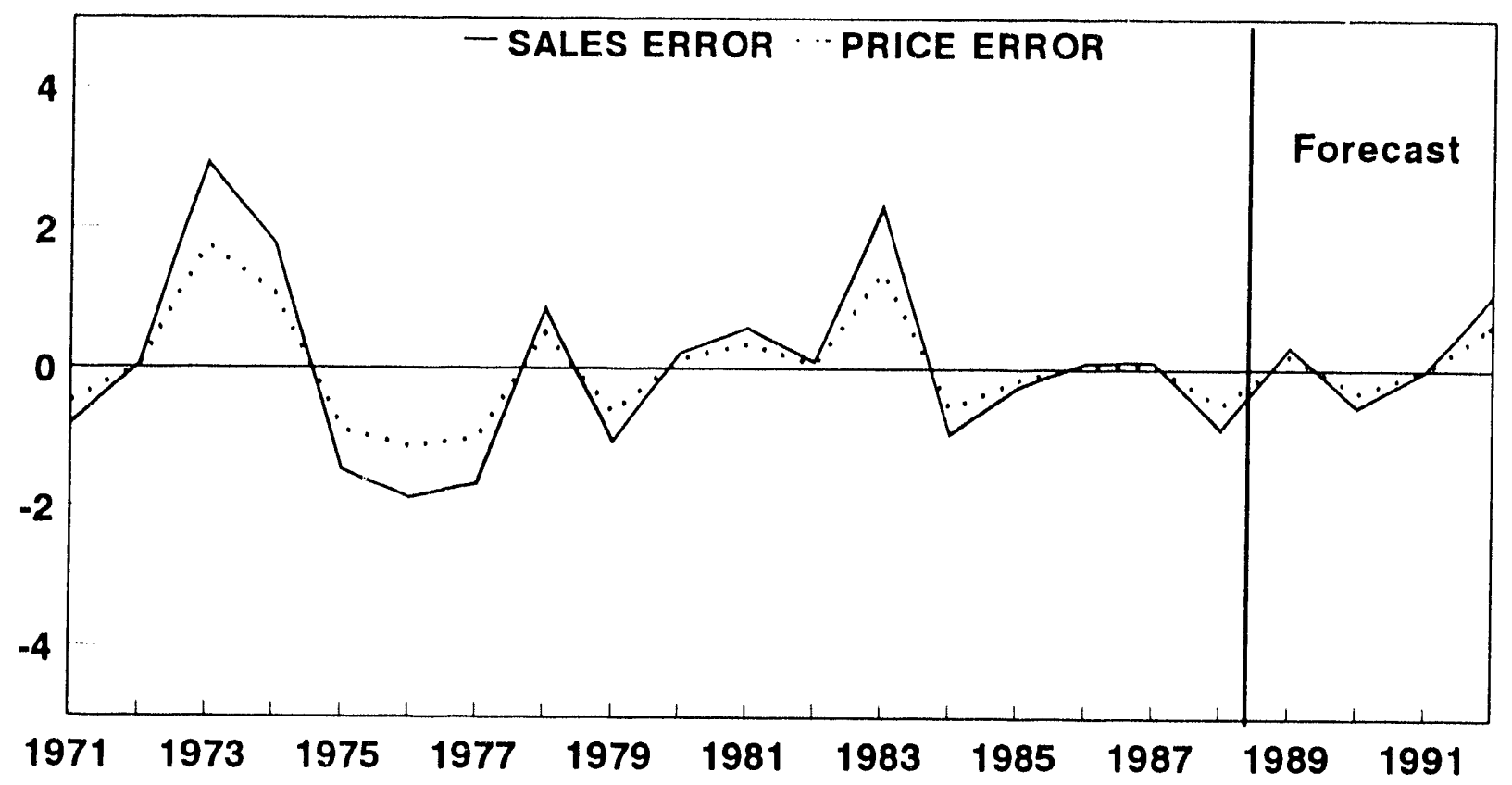

Fig. 5. The errors in retail electricity sales and prices associated with statistical recoupling, based on the model of aggregate electricity use for PSCo. The errors in price equal $52 \%$ of the errors in sales.

Figure 6 shows the performance of the SR models for each of the five utilities." All these models used total electricity use $(\mathrm{GWh})$ as the dependent variable in a simple linear equation with about six independent variables. With one exception (1992 for SCE), the errors are all less than $2 \%$. And the three-year average error for each utility is less than $1 \%$, except for SCE, which has a three-year error of $-1.3 \%$. The 15 data points in Fig. 6 show no pattern, either across utilities or with time. This lack of a pattern is encouraging because it suggests that the errors associated with SR are largely random and that, on average, the price changes caused by SR will approach zero.

These analyses of data from five utilities showed great similarity in results. This regularity suggests that $\mathrm{SR}$ is likely to yield consistent results from year to year and from utility to utility.

The percentage change in electricity price associated with SR would be 25 to $50 \%$ lower than the percentage change in electricity sales, as discussed above. 


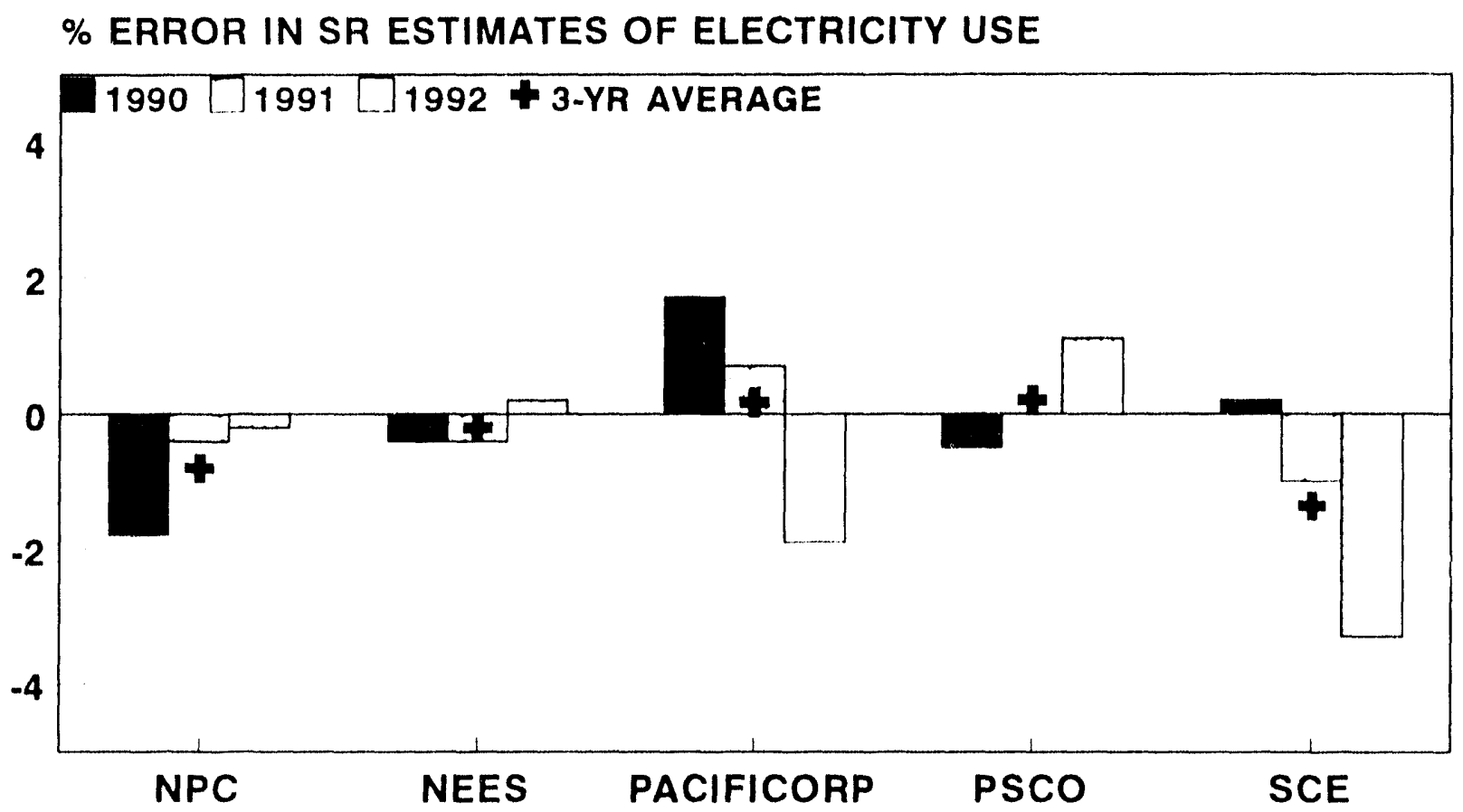

Fig. 6. Errors in SR estimates of total (residential plus commercial plus industrial) electricity use for 1990, 1991, and 1992.

\section{NUMBER OF OBSERVATIONS NEEDED}

An important issue associated with $\mathrm{SR}$ is the minimum number of observations needed to obtain reliable and stable estimates of electricity use during the simulation period. To examine this issue, I used the monthly data from NEES, which covers 1980 through 1992. I tested models of total electricity use (residential, commercial, and industrial) with eight, seven, six, five, four, and three years of data (i.e., with 96 to 36 observations). These models all included an autocorrelation term with a 12-month lag, which is why the first year of data (1980) was not available. The last three years of data (1990) through 1992) were not used in the estimation so that they could be used in a simulation test.

Table 4 summarizes the results for these six models. Each model had the same explanatory variables: number of customers, heating degree days, cooling degree days, average electricity price, and industrial production.

All the models, even the one with only 36 observations had very high explanatory power, with $\mathrm{R}^{2}$ values of $97 \%$ or higher. The coefficients for number of customers, heating degree days, and cooling degree days were significant at the $100 \%$ level for every model. However, the coefficients for electricity price and industrial production were less significant for the models with fewer observations. Even here, however, the coefficients were significant 
at the $95 \%$ level or better for all the models with 60 or more observations. These two coefficients were not significant in the models with 36 or 48 observations.

Table 4. Statistical properties and performance of models of total electricity use for NEES retail customers

\begin{tabular}{|c|c|c|c|c|c|c|}
\hline & \multicolumn{6}{|c|}{ Number of observations in model } \\
\hline & 96 & 84 & 72 & 60 & 48 & 36 \\
\hline Adjusted $\mathrm{R}^{2}$ & 0.989 & 0.988 & 0.986 & 0.985 & 0.978 & 0.972 \\
\hline \multicolumn{7}{|l|}{ Significance of coefficients } \\
\hline Number of customers & 1.00 & 1.00 & 1.00 & 1.00 & 1.00 & 1.00 \\
\hline Heating degree days & 1.00 & 1.00 & 1.00 & 1.00 & $1 .(0)$ & 1.00 \\
\hline Cooling degree days & 1.00 & 1.00 & 1.00 & 1.00 & 1.00 & 1.00 \\
\hline Electricity price & 0.99 & 0.95 & 0.97 & 0.98 & 0.89 & 0.82 \\
\hline Industrial production & 1.00 & 1.00 & 1.00 & 0.98 & (0.77 & 0.30 \\
\hline $\begin{array}{l}\text { Total error in simulation } \\
\text { period, } 1990 \text { to } 1992(\%)\end{array}$ & +1.2 & +0.9 & -1.0 & +0.5 & +1.5 & +4.8 \\
\hline
\end{tabular}

The magnitudes of the coefficients for number of customers, heating degree days, and cooling degree days were quite stable across these models. The maximum variation across these three variables and six models was $15 \%$. The variation in the magnitudes of the coefficients for electricity price and industrial production were higher. To illustrate, the electricity price coefficient in the model with 60 observations was $36 \%$ higher than the coefficient in the model with 96 observations.

Figure 7 shows the simulation performance of these six models for the years 1990, 1991, and 1992. All the models, except the one with only 36 observations, gave accurate estimates of total electricity use. These five models also gave consistent estimates from year to year: a slight underestimate of 1990 electricity use (-().5\%), a slight overestimate in 1991 $(+0.4 \%)$, and a larger overestimate in $1992(+0.7 \%)$.

I conducted a similar experiment with a utility that provided quarterly data rather than monthly data. The results, using PSCo data, are essentially the same (Table 5). As the number of observations used to estimate the model increases, the simulation accuracy also increases. For example, the model with 73 observations had a smaller three-year error $(0.5 \%)$ than did any of the models with fewer observations; the same is true for the model with 65 observations, and so on. 


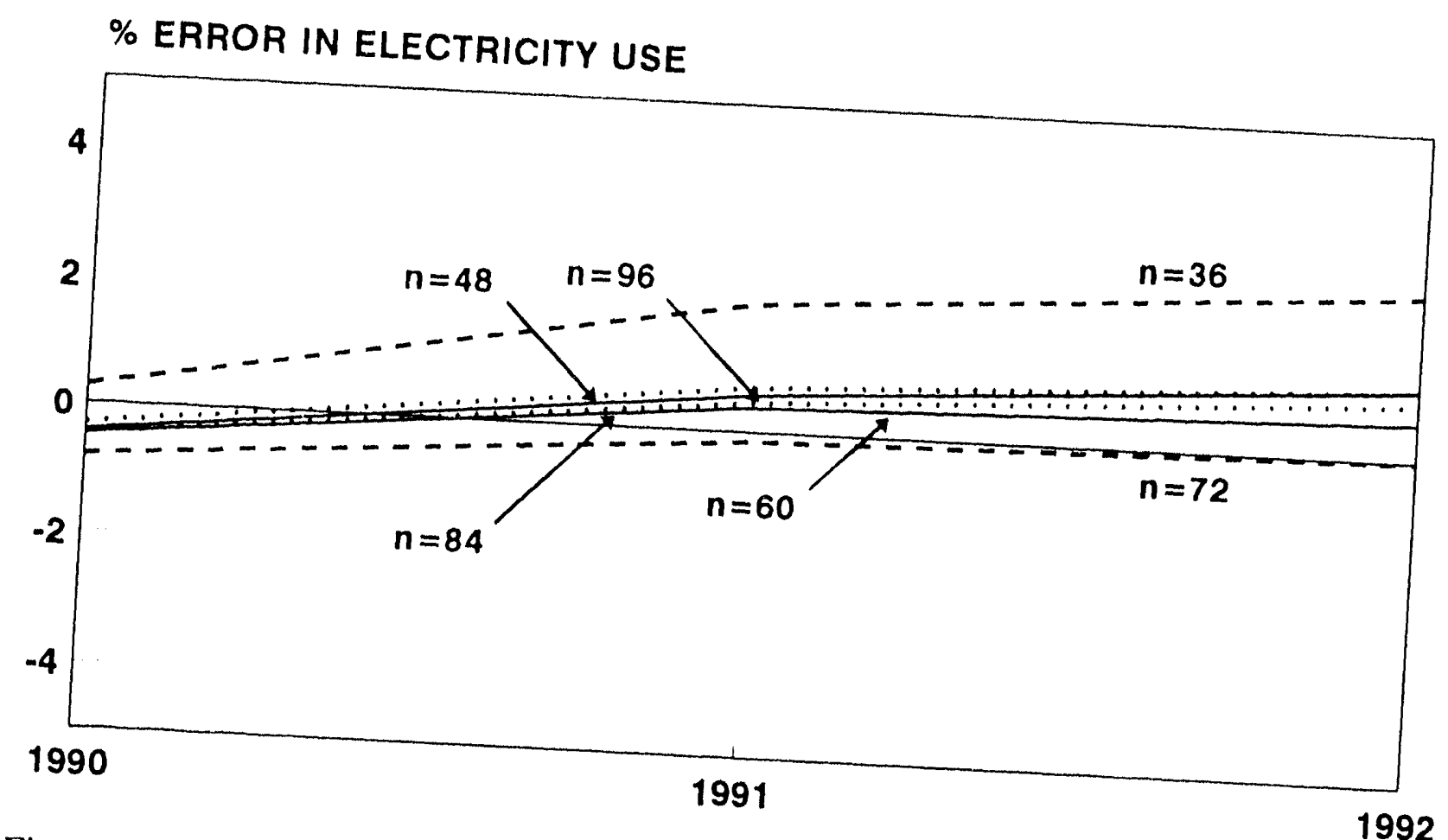

Fig. 7. Simulation results obtained with six models (with 36 to 96 observations) of
total retail electricity use for NEES.

Table 5. Statistical properties and performance of models of total electricity use for
PSCo retail customers

\begin{tabular}{lccccccc} 
& \multicolumn{7}{c}{ Number of observations in model } \\
\cline { 2 - 7 } & 73 & 65 & 57 & 49 & 41 & 3.3 \\
\hline Adjusted $\mathrm{R}^{2}$ & 0.992 & 0.990 & 0.988 & 0.983 & 0.976 & 0.970 \\
Significance of coefficients & & & & & & \\
$\quad$ Number of customers & 1.00 & 1.00 & 1.90 & 1.00 & 1.00 & 1.00 \\
Heating degree days & 1.00 & 1.00 & 1.00 & 1.00 & 1.00 & 1.00 \\
Cooling degree days & 1.00 & 1.00 & 1.00 & 1.00 & 1.00 & 1.00 \\
Electricity price & 0.94 & 0.90 & 0.98 & 0.99 & 0.95 & 0.75 \\
Income & 0.99 & 1.00 & 1.00 & 1.00 & 1.00 & 0.98 \\
Total error in simulation & & & & & & & \\
period, 1990) to $1992(\%)$ & +0.5 & +1.3 & +2.7 & +3.9 & +4.5 & +5.3 \\
\hline
\end{tabular}


Generally speaking, the more observations used to estimate the model, the more accurate it is over the simulation period. However, over a broad range of sample sizes (above 40 or so), the results are quite stable in terms of both model estimation (explanatory power and statistical significance of the coefficients) and simulation (accuracy of predictions). Also, the range in model estimates increases from 1990 to 1991 and again to 1992. 


\section{IMPLEMENTING STATISTICAL RECOUPLING}

Implementation involves two steps. In the first step, the utility, working with other interested parties, develops ahernative statistical models. After review of these models, the company and other parties agree on a particular model to use, subject to approval by the PUC. For purposes of this example, I use the PacifiCorp quarterly data from 1978 through 1989 on electricity sales and its key determinants." Aggregation of the data across the three primary classes (residential, commercial, and industrial) yields the following "preferred" model (Table 6):

Total electricity use (GWh/quarter $)=-564$ (CONST)

$+0.00660^{*}$ Number of customers (CTOT)

$+0.113 *$ Heating degree days (HDD)

$+0.347^{*}$ Cooling degree days (CDD)

- $61.7 *$ Retail electricity price (PTOT)

$+177 *$ Industrial output (INDOUT)

Table 6. Statistical properties for model of PacifiCorp total Utah sales (GWh/quarter)

\begin{tabular}{|c|c|c|c|c|}
\hline Term & Coefficient & Standard error & t-statistic & Significance \\
\hline $\begin{array}{l}\text { CTOT } \\
\text { PTOT } \\
\text { HDD } \\
\text { CDD } \\
\text { INDOUT } \\
\text { CONST } \\
\text { _AUTO }(-1)\end{array}$ & $\begin{array}{r}0.006603 \\
-61.723168 \\
0.113035 \\
0.346906 \\
176.921646 \\
-563.573372 \\
0.415613\end{array}$ & $\begin{array}{r}0.001354 \\
31.555730 \\
0.013195 \\
0.035360 \\
111.595417 \\
334.283099 \\
0.148275\end{array}$ & $\begin{array}{r}4.875088 \\
-1.956005 \\
8.566718 \\
9.810710 \\
1.585385 \\
-1.685916 \\
2.802979\end{array}$ & $\begin{array}{l}0.999982 \\
0.942527 \\
1.000000 \\
1.000000 \\
0.879246 \\
0.900402 \\
0.992229\end{array}$ \\
\hline \multicolumn{2}{|c|}{$\begin{array}{l}\text { Sample size } 47 \\
\text { Mean } 2496 \\
\text { R-square } 0.968 \\
\text { Durbin-Watson } 1.981 \\
\text { Forecast error } 62.69 \\
\text { MAPE } 0.01869\end{array}$} & \multicolumn{3}{|c|}{$\begin{array}{l}\text { Number of parameters } 7 \\
\text { Standard deviation } 326.9 \\
\text { Adjusted R-square } 0.9632 \\
\text { Ljung-Box }(18)=19.99 \quad \mathrm{P}=0.6664 \\
\text { BIC } 77.04 \\
\text { RMSE } 57.83\end{array}$} \\
\hline
\end{tabular}

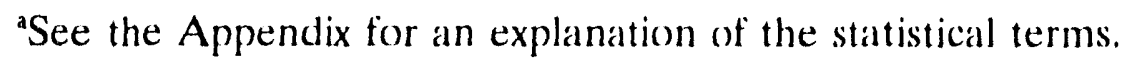

The second step involves application of the model to compute allowed sales and revenues for the years 1990, 1991, and 1992. Results for a case with no DSM programs are

I did not use the data for 1990), 1991, and 1992 in estimating the statistical model; these datit were used only to test the accuracy of the SR model in simulation. 
shown in Table 7; see especially the last two lines of this table. For 1990, based on actual values of heating and cooling degree days, industrial output, electricity price, and number of customers, the model computes allowed sales of $12,615 \mathrm{GWh}, 1.7 \%$ more than the actual sales of 12,398 . This yields an increase in electricity price of $0.05 \mathrm{c} / \mathrm{kWh}$ to be applied in 1991 to the base value of $5.36 \mathrm{c} / \mathrm{kWh}$ (the weighted average of the retail prices for each customer class approved in the most recent rate case). Thus, the average retail electricity price in 1991 is, as shown in Table 7, 5.41 c/kWh.

\section{Table 7. Implementation of statistical recoupling in Utah with no DSM programs}

\begin{tabular}{|c|c|c|c|c|c|}
\hline & 1990 & 1991 & 1992 & 1993 & $\begin{array}{c}\text { Three-year } \\
\text { effect }\end{array}$ \\
\hline $\begin{array}{l}\text { Gross sales (GWh) } \\
\text { DSM effect (GWh) } \\
\text { Net sales (GWh) } \\
\text { Average retail price ( } / \mathrm{kWh})^{\text {a }} \\
\text { Revenues (million } \$ \text { ) }\end{array}$ & $\begin{array}{c}\text { statist } \\
12398 \\
0 \\
12398 \\
5.38 \\
667\end{array}$ & $\begin{array}{c}1 \text { reco } \\
12839 \\
0 \\
12839 \\
5.36 \\
688\end{array}$ & $\begin{array}{l}1 \text { ing } \\
13427 \\
0 \\
13427 \\
5.12 \\
687\end{array}$ & 5.12 & $\begin{array}{l}5.20 \\
1376\end{array}$ \\
\hline $\begin{array}{l}\text { Actuals } \\
\text { Average retail price ( } \quad \text { With } \mathrm{kt} \text { (kh) } \\
\text { Revenues (million } \$)\end{array}$ & $\begin{array}{l}\text { tatistic } \\
\begin{array}{r}5.38 \\
667\end{array}\end{array}$ & $\begin{array}{r}\text { recour } \\
5.41 \\
695\end{array}$ & $\begin{array}{l}\text { ng } \\
5.14 \\
690\end{array}$ & 5.07 & $\begin{array}{l}5.21 \\
1385\end{array}$ \\
\hline $\begin{array}{l}\text { Heating degree days } \\
\text { Cooling degree days } \\
\text { Utah industrial output } \\
\text { Real electricity price } \\
\text { Number of customers (thousands) }\end{array}$ & $\begin{array}{r}5370 \\
1346 \\
11.2 \\
4.68 \\
\quad 491\end{array}$ & $\begin{array}{r}5795 \\
1102 \\
11.3 \\
4.47 \\
502\end{array}$ & $\begin{array}{r}5153 \\
1189 \\
11.8 \\
4.16 \\
506\end{array}$ & & \\
\hline $\begin{array}{l}\text { Allowed } \\
\text { Sales (GWh) } \\
\text { Revenues (million } \$ \text { ) } \\
\text { Price adjustment, next year } \\
\text { \&/kWh } \\
\text { \& change }\end{array}$ & $\begin{array}{r}12615 \\
674 \\
0.05 \\
1.0\end{array}$ & $\begin{array}{r}12925 \\
691 \\
0.02 \\
0.4\end{array}$ & $\begin{array}{r}13173 \\
680 \\
-0.05 \\
-1.0\end{array}$ & & $\begin{array}{l}1371 \\
0.02 \\
0.33\end{array}$ \\
\hline
\end{tabular}

aThe year-to-year changes in average retail prices reflect the changes, both within and across customer classes, in the relative amounts of electricity used.

In 1991, the winter is more severe, the summer is milder, the number of customers grows, industrial output increases slightly, and electricity prices fall, leading to an increase in allowed sales, to 12,925 GWh. Actual sales grow also, to 12,839 GWh. This difference between actual and allowed sales in 1991 leads 10 a $0.02 \mathrm{c} / \mathrm{kWh}$ price increase $\mathrm{to}$ be applied to the base price in 1992 .

To produce the allowed sales estimates in Table 7, the coelficients in Table 6 for CTOT, PTOT, INDOUT, and CONST must be multiplied by 4 to convere from quarterly to annual estimates. Also, the autocorrelation term (AUTO|-1]) in Table 6 is set 10 zero for simulation. 
In 1992, allowed sales are slightly below actual sales, leading to a $0 .(15 \mathrm{c} / \mathrm{k}$ Wh price decrease applied in 1993. During this three-year period, SR would have increased prices slightly for two years and then decreased prices slightly in the third year. The overall effect is an increase in electricity price of $0.02 \mathrm{c} / \mathrm{kWh}(0.33 \%)$ for the three years. The percentage changes in electricity price are less than two-thirds the percentage errors in the SR model because of the adjustments in going from the retail electricity price $10 \mathrm{P}_{\mathrm{f}}$. A typical residential customer with a base price of, say, $6 .(0 \mathrm{c} / \mathrm{kWh}$ would have paid $6 .(15 \mathrm{c} / \mathrm{kWh}$, $6.02 \mathrm{c} / \mathrm{kWh}$, and $5.95 \mathrm{c} / \mathrm{kWh}$ for electricity in 1991,1992 , and 1993 had SR heen in place.

Table 8. Implementation of statistical recoupling in Utah with DSM programs

\begin{tabular}{|c|c|c|c|c|c|}
\hline & 1990 & 1991 & 1992 & 1993 & $\begin{array}{c}\text { Three-year } \\
\text { effect }\end{array}$ \\
\hline $\begin{array}{l}\text { Gross sales (GWh) } \\
\text { DSM effect (GWh) } \\
\text { Net sales (GWh) } \\
\text { Average retail price }(G / \mathrm{kWh})^{a} \\
\text { Revenues (million } \$ \text { ) }\end{array}$ & $\begin{array}{c}\text { statist } \\
12398 \\
-60 \\
12338 \\
5.38 \\
664\end{array}$ & $\begin{array}{c}12839 \\
-120 \\
12719 \\
5.36 \\
682\end{array}$ & $\begin{array}{l}1 \text { ing } \\
13427 \\
-180 \\
13247 \\
5.12 \\
678\end{array}$ & 5.12 & $\begin{array}{l}5.20 \\
1360\end{array}$ \\
\hline $\begin{array}{l}\text { Actuals } \\
\text { Average retail price }(\xi / \mathrm{kWh}) \\
\text { Revenues (million } \$)\end{array}$ & $\begin{array}{r}\text { atisti } \\
5.38 \\
664\end{array}$ & $\begin{array}{r}\text { recou } \\
5.43 \\
690\end{array}$ & $\begin{array}{r}9 \\
5.17 \\
685\end{array}$ & 5.10 & $\begin{array}{l}5.23 \\
1375\end{array}$ \\
\hline $\begin{array}{l}\text { Allowed } \\
\text { Sales (GWh) } \\
\text { Revenues (million } \$ \text { ) } \\
\text { Price adjustment, next year } \\
\text { \&/kWh } \\
\text { \& change }\end{array}$ & $\begin{array}{r}12615 \\
672 \\
0.07 \\
1.3\end{array}$ & $\begin{array}{r}12925 \\
688 \\
0.05 \\
0.9\end{array}$ & $\begin{array}{r}13173 \\
676 \\
-0.02 \\
-0.3\end{array}$ & & $\begin{array}{l}1364 \\
0.10 \\
1.86\end{array}$ \\
\hline
\end{tabular}

${ }^{a}$ To keep this example simple, these prices do not reflect recovery of DSM-program costs.

If PacifiCorp had run DSM programs that cut electricity use during this period, the mechanics of implementing SR would have been unchanged. In this example, I assume that the company's DSM programs cut electricity use by an incremental $0.5 \%$ each year (Table $8)$. In 1992, sales are lower by almost $1.5 \%$.

Because of the company's assumed DSM programs, the price decreases are slightly smaller and the price increases are slightly larger than was the case with no DSM programs. During the three-year period, prices increase an average of $0.1 \%$ year without DSM programs and $0.6 \%$ year with DSM programs. Thus, SR works as expected: it yields only

These DSM-induced short-term price increases are oftset by price decreases later on and by lower total costs of meeting electric-energy service needs. 
small changes in electricity price and it removes the disincentive for PacifiCorp DSM programs.

This example covers a three-year implementation period, which, I believe, is appropriate. Retention of the same model for several years is administratively simple because it avoids conflict over model form and variables. However, the forecasts made with a statistical model will become less accurate as time goes on. On the other hand, estimating new models every year invites regulatory complications and, more important, is probably not necessary to maintain accuracy. Although SR can be implemented and updated as part of a regular rate-case cycle (e.g., the three-year cycles in California and New York), the method can be implemented and updated independent of rate cases. 


\section{OTHER ISSUES FOR STATISTICAL RECOUPLING}

\section{COST-CONTROL AND ECONOMIC-DEVELOPMENT EFFORTS}

Statistical recoupling should have no effect on a utility's efforts to control its costs, keep electricity prices low, and promote economic development. Because the mechanism focuses on revenues and not on earnings, a utility would continue to have the same incentive it always had to hold down costs.

Although the mechanism removes the incentive to build uneconomic load, it also removes the disincentive to promote customer energy efficiency. As the Connecticut Department of Public Utility Control (1991) noted "conservation is an essential tool to keep Connecticut business competitive and attract new companies to the state."

A utility operating under SR would continue to run beneficial load-building programs (e.g., to promote economic development or to improve local environmental quality) because its long-term profits depend on the health of the economy in its service area. If local industries do poorly or go out of business, the utility will lose not only those industrial sales but all the associated residential and commercial sales, too. In the short term (i.e., between rate cases), the utility would have an incentive to promote economic sales and a disincentive to promote sales that did not improve the local economy (i.e., that were not reflected in the economic variable in the SR model).

For example, Southern California Edison (1992) runs load-building programs to help its commercial and industrial customers meet environmental regulations and therefore remain in the SCE service area. These programs focus on local air quality; examples include the Volatile Organic Compound Reduction Test Program for Dry Cleaners and a program to reduce $\mathrm{NO}_{\mathrm{x}}$ emissions from fossil-fuel boilers through "retrofits, heat recovery equipment, emission reduction technologies, electric boilers, heat pumps, and thermal storage applications." Because SCE's earnings are independent of electricity sales (because of ERAM, discussed above), the California PUC can be more confident that SCE runs these programs to help customers.

To the extent that a utility promotes load growth that increases economic activity, SR will increase allowed utility revenues and therefore earnings. For example, the model presented above for NEES uses Massachusetts industrial output as an explanatory variable. The inclusion of this variable in the model means that any NEES economic-development activity that increases output will increase NEES's allowed reveliues under SR. If NEES encourages a firm to build a new factory in Massachusetts, the output generated by that factory will increase NEES's allowed revenues. 
However, if the company boosts loads in a way that does not increase output in the service area, its revenues and earnings will not increase. In other words, the company, under SR, has an incentive to promote sales that help the local economy. However, NEES receives no compensation for sales that do not benefit customers in general (i.e., undifferentiated load growth). These are very desirable features of $S R$, in my view.

As Bartsch and DeVaul (1993) comment:

Utilities traditionally have supported economic development initiatives because they depend upon the fiscal fortunes of their service territories. Most follow the 'smoke-stack' model of industrial recruitment, however, often offering low incentive rates to attract new business. Few actually undertake an active effort to invest directly in business modernization or to help firms improve their cash-flow positions by managing energy needs and costs.

Yet by linking energy efficiency and competitiveness strategies, utilities can lower businesses' operating costs and upgrade their process technologies.

Statistical recoupling provides an incentive for utilities to link efficiency and competitiveness because the method removes the disincentive to reduce electricity sales while retaining an incentive for economic growth.

\section{BIAS IN MODEL SELECTION}

To assess the possibilities of manipulating the models used in SR, I developed various models of total electricity use. I used the PacifiCorp data for Utah to conduct this exercise, the details of which are in the Appendix.

I estimated models of total electricity use (combining data from the residential, commercial, and industrial classes) as well as models of total electricity use per customer. Three of the four models in each set are linear models, while the fourth model uses the logarithmic form for electricity use, electricity price, and the economic variable. The first three models differ in their use of an economic variable: industrial output, manufacturing employment, and industrial output per customer.

Table 9 and Fig. 8 show how these eight models differ in the accuracy of their estimates of electricity use for 1990, 1991, and 1992, as well as the cumulative (three-year) error. These models were all estimated using data from 1978 through 1989. 
Table 9. Simulation errors ob ained with different models of electricity use for PacifiCorpa

\begin{tabular}{|c|c|c|c|c|c|c|c|c|}
\hline & \multicolumn{8}{|c|}{ Percent error } \\
\hline & \multicolumn{4}{|c|}{ Total sales models } & \multicolumn{4}{|c|}{ Sales per customer models } \\
\hline & $\overline{(1)}$ & $(2)$ & $(3)$ & (4) & $(5)$ & $(6)$ & (7) & $(8)$ \\
\hline 1990 & +1.7 & +2.8 & +1.6 & +2.7 & +2.0 & +2.6 & +1.6 & +2.2 \\
\hline 1991 & +0.7 & +1.4 & +0.5 & +2.3 & +0.9 & +0.4 & +0.1 & +1.3 \\
\hline 1992 & -1.9 & -2.0 & -2.2 & +0.1 & -1.5 & -3.9 & -2.4 & -2.1 \\
\hline \multicolumn{9}{|c|}{ Three-year } \\
\hline error & +0.5 & +2.2 & +0.1 & +5.1 & +1.4 & -0.9 & -() .7 & +1.4 \\
\hline
\end{tabular}

${ }^{a}$ The Appendix provides details on each of these models.

\section{\% ERROR IN SR ESTIMATES OF ELECTRICITY SALES}

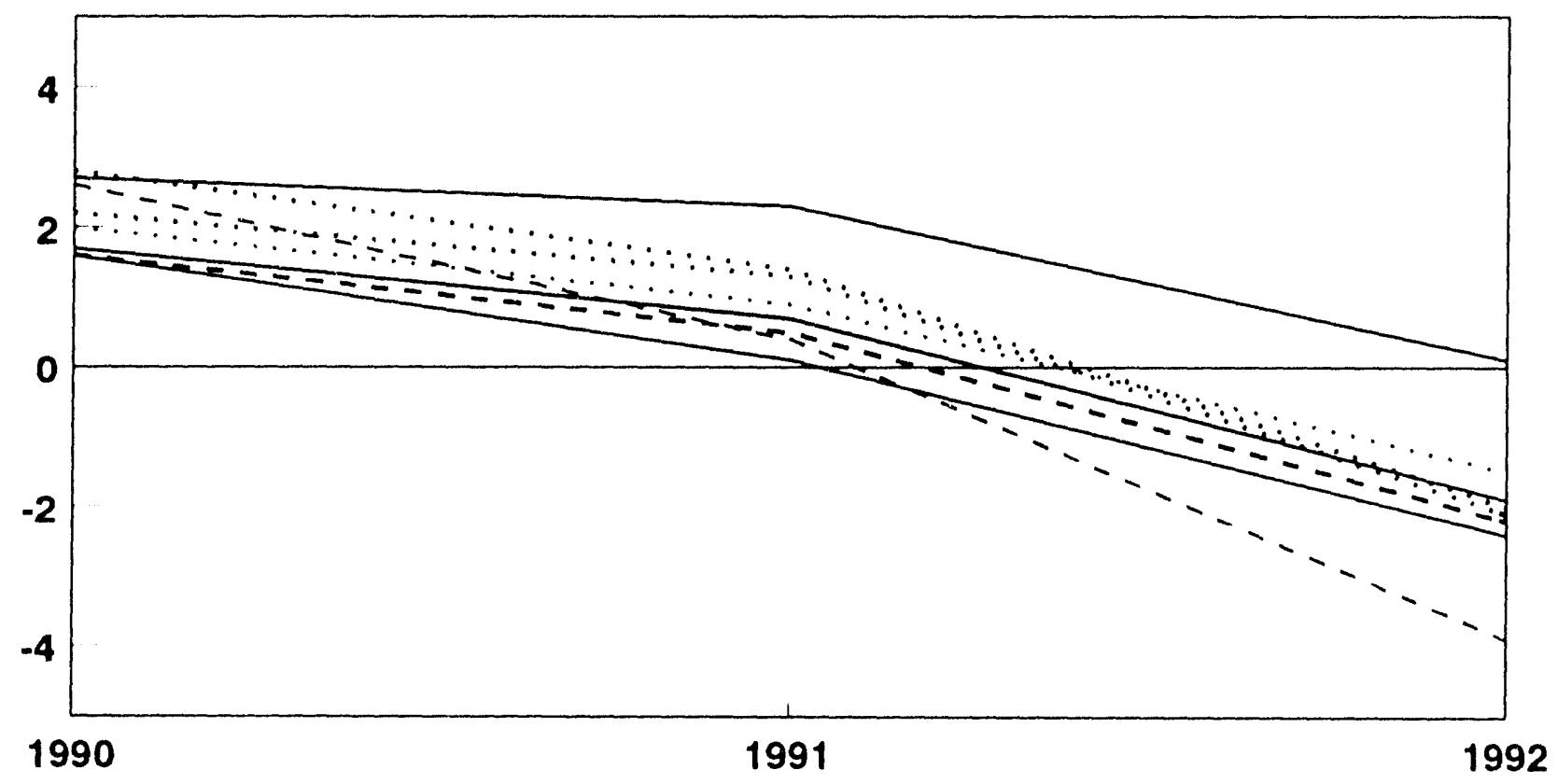

Fig. 8. Simulation errors obtained with eight models of electricity use for PacifiCorp.

The models all overpredict electricity use in 1990 and 1991 . All but one of the models underpredict 1992 electricity use. The range in predictions among the models increases from year to year, from 1.2 percentage points in 1990) to 2.2 percentage points in 1991, and 4.0 percentage points in 1992. These results, not surprisingly, show that the accuracy of the models' estimates decreases as one moves further away from the historical estimation period. 
This phenomenon was also observed in the comparison of six models for NEES, which was discussed above (Fig. 7).

Given this range in model performance, how might a utility seeking to maximize its allowed revenues in future years pick among these models? Table 9 shows that Model 4 yields the largest positive error of these eight models, a $5.1 \%$ overprediction of sales. Comparing the coefficients of this model with those of Model 8 , the other log-log model, shows that Model 4 has a higher electricity-price coefficient and a lower industrial-output coefficient.

If the utility knew, in 1989, that industrial output would grow slowly during the next three years and that the mix of electricity sales would shift to the industrial sector (which pays a lower price than does the residential class), then the utility would pick Model 4 over Model 8. On the other hand, if the utility thought that the economy would grow rapidly and that the mix of sales would not change (or would shift to the residential sector), then it would want to use Model 8 . Absent good information on such future trends, the utility has no basis for selecting one model over another.

One can pick any pair of models among these eight and go through the same type of exercise to show the difficulty of selecting a model to achieve a desired outcome. Consider Models 1 and 2 as another example. The state's consumer advocate might like a model that lowered the utility's authorized revenue. So it would prefer, after the fact, Model 1 to Model 2. But in 1989, how would it know whether the number of customers would grow slowly (in which case it would pick Model 2) or whether the summers would be especially hot and the winters unusually mild (in which case it would pick Model 1)? What would the consumer advocate do if it thought that the number of customers would grow slowly (which favors Model 2) and that the summers would be mild and the winters harsh (which favors Model !)?

This examination of alternative models and their simulation results leads to three conclusions:

- It is very difficult - absent reliable information on future changes in the number of customers, the weather, and the economy - to select a model that will achieve a desired outcome. Thus, manipulation is not a problem with SR.

- The range in estimates across these models is quite small, which suggests that SR results are robust.

- The range in estimates increases from one year to the next, which suggests that these models should be re-estimated every few years. 


\section{EFFECTS OF PAST UTILITY DSM PROGRAMS}

Because the models used in SR are hased on historical data, they will automatically include the effects of any past load-building or energy-efficiency programs that the utility might have run. Will the effects of such past programs bias the estimates obtained with the statistical-recoupling models?

Hypothetical Example

To explore this issue, I used the data from PacifiCorp and added the effects of a hypothetical load-building program. This hypothetical program hegan in 1985, with a first quarter sales increase of $0.15 \%$. The program continued unchanged with each quarter's load increment added to the cumulative effects of all past increments such that sales in 1989 were increased $2.5 \%$ because of these load-building efforts. By assumption, this program had no effect on the local economy (i.e., Utah industrial output).

I made two alternative assumptions for the $1990-1992$ simulation period: (1) the utility continued its load-building program unchanged during these three years or (2) the utility stopped load-building programs at the end of 1989 (Fig. 9). In both cases, the effects of past load-building programs continued through the simulation period. I used the same linear model formulation of total electricity use shown in Table 6 ; the coefficients are different because of the load-building effects from 1985 through 1989.

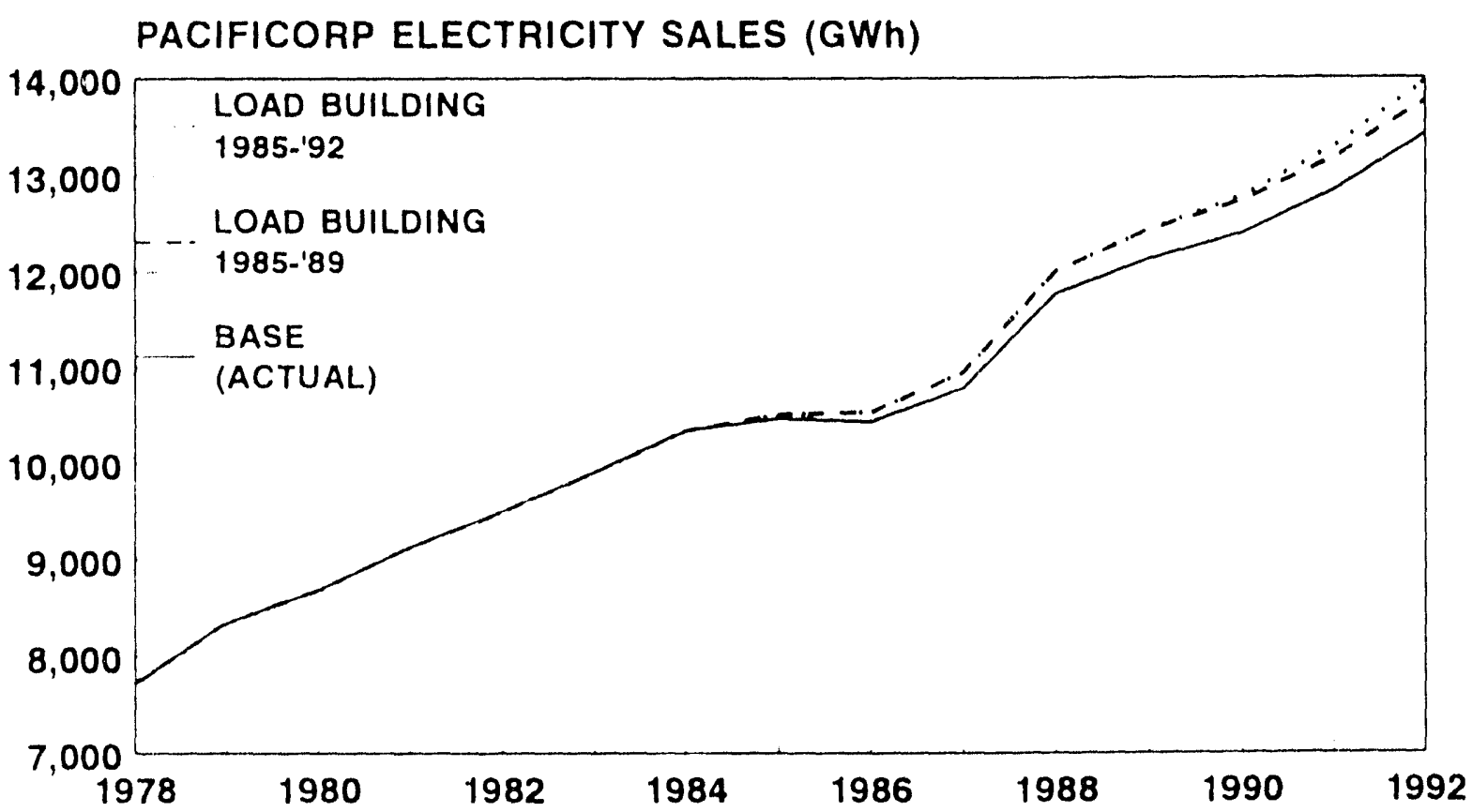

Fig. 9. PacifiCorp retail electricity sales for its Utah service area. The solid line is actual sales. The dashed line assumes that a load-building program was in operation from 1985 through 1989. The dotted line assumes that the loadbuilding program continued to operate through 1992. 
The simulation results for the case with continuation of load building are quite similar to those obtained with no load building (compare the first column in Table 9 with the first column in Table 10). However, the errors are consistently more positive for the case when load-building stops at the end of 1989 . Over the three-year simulation period, the difference amounts to an extra $2.7 \%$ of sales if the utility had stopped its load-building programs at the end of 1989.

Table 10. Simulation errors obtained with a model of total PacifiCorp electricity use with a load-building program that was run from 1985 through either 1989 or $1992^{2}$

\begin{tabular}{lcc}
\hline & $\begin{array}{c}\text { Load building } \\
\text { continued through 1992 }\end{array}$ & $\begin{array}{c}\text { Load building } \\
\text { stopped in 1989 }\end{array}$ \\
\hline 1990 & 1.7 & 2.1 \\
1991 & 0.3 & 1.2 \\
1992 & -2.4 & -1.0 \\
Three-year error & -0.4 & +2.3 \\
\hline
\end{tabular}

aThis load-building program, begun in 1985 , increased sales by $2.5 \%$ in 1989 . The difference between the two cases in 1992 was $1.5 \%$ of sales.

These results are expected. The model and its coefficients used to estimate electricity use for 1990, 1991, and 1992 are exactly the same in both cases. Therefore, the estimated results are the same in both cases. The errors are greater in the second case because the "actual" values of electricity use are lower when load building stops at the end of 1989.

These results show that SR overestimates allowed revenues if the utility had loadbuilding programs that were discontinued at the start of the statistical-recoupling implementation period. The reverse is also true. If the utility had run energy-efficiency programs that were cancelled when SR was being implemented, the utility would underrecover. This error in SR may, fortuitously, lead to good policy. The error encourages utilities to stop load-building programs that do not promote economic growth and to continue energy-efficiency programs.

If the statistical models include explanatory variables that capture the effects of the utility's DSM programs (e.g., the utility's quarterly budget for load-huilding or energyefficiency programs), this problem might not occur. However, the historical effects of utility DSM programs are likely to be small and difficult to capture in such a simple statistical model.

The practical issue is whether historical load-huilding programs that do not affect the local economy are likely to have a large enough effect on past and future electricity sales to 
have measurable effects. If the load-building programs were small, the hias in simulation results obtained with SR would, likewise, be small.

\section{Analysis of Southern California Edison Data}

Southern California Edison (1993) calculates, on a quarterly basis, what electricity sales would have been for each sector absent the effects of SCE conservation programs, mandatory appliance and building efficiency standards, and bypass. These adjustments increased from $4 \%$ of sales in 1980 to $15 \%$ in 1992 . Thus, these data provide an opportunity to examine empirically the performance of SR when (1) a utility has DSM programs in place, (2) has estimates of the effects of these programs (as well as other factors) on electricity use, and (3) when the effect of these programs on sales is nontrivial.

I tested different specifications of a model of SCE retail electricity sales with and without a variable that is SCE's estimate of the change in sales caused by the factors listed above. The coefficients of this change variable were always statistically significant at the $90 \%$ level; the magnitude of this coefficient ranged from 0.6 to 1.1. A coefficient greater than 1.() implies that the SCE estimates of the electricity savings caused by these factors was too low, a coefficient of $1 .($ implies that the SCE estimates are exactly correct, and so on.

In most cases, the model that included this additional factor had more accurate estimates of actual sales for 1990, 1991, and 1992 than did the model without this variable (Table 11). However, the models that did not include this change variable also had very good predictive powers. So, even in a case where the adjustments are substantial (15\% in 1992 for SCE), a model that ignores these effects can perform well.

Table 11. Performance of models of electricity sales for Southern California Edison with and without an explanatory variable for the effects of DSM and other factors

\begin{tabular}{lccccc}
\hline $\begin{array}{l}\text { Variables } \\
\text { in model }\end{array}$ & $\begin{array}{c}\text { Number of } \\
\text { explanatory } \\
\text { variables }\end{array}$ & $\begin{array}{c}\text { Number } \\
\text { significant } \\
\text { at } 99 \%\end{array}$ & $\mathrm{R}^{2}$ & $\begin{array}{c}\text { Cofficient } \\
\text { of estimated } \\
\text { electricity savings }\end{array}$ & $\begin{array}{c}\text { Three-year } \\
(199()-92) \\
\text { error }(\%)\end{array}$ \\
\hline $\begin{array}{l}\text { Employment, CDD, } \\
\text { and price }\end{array}$ & 3 & 3 & 0.988 & - & -1.4 \\
Unemployment, CDD, & 3 & 4 & $(0.991$ & -1.3 & -1.7 \\
and price & 4 & 2 & 0.99() & - & -1.3 \\
Unemployment, CDD, & 4 & 4 & $(0.993$ & -1.1 & $-(1.6$ \\
HDD, and price & 5 & 3 & 0.992 & - & -1.5 \\
\end{tabular}




\section{EFFECTS OF DIFFERENTIAL DSM PROGRAMS}

The statistical recoupling models all deal with electricity use and not demand (GWh and not $\mathrm{MW}$ ). In addition, the aggregate models (which are simpler to estimate and which perform better than separate models for each customer class) include all customer classes in one equation.

These features of SR raise questions about its accuracy in estimating the net lost revenues associated with DSM programs if (1) these programs affect different customer classes differentially or (2) these programs have different effects on energy use and demand. To explore the performance of SR with different types of DSM programs, I created a hypothetical utility with three customer classes and the rate structures shown in Table 12.

Table 12. Rate structures and electricity use by customer class for a hypothetical utility

\begin{tabular}{|c|c|c|c|c|c|c|}
\hline & \multicolumn{3}{|c|}{ Rutail tariffs } & \multirow{2}{*}{$\begin{array}{l}\text { Customers } \\
\text { (thousands) }\end{array}$} & \multirow{2}{*}{$\begin{array}{l}\text { Energy } \\
\text { (GWh) }\end{array}$} & \multirow{2}{*}{$\begin{array}{c}\text { Demand } \\
(\mathrm{MW})\end{array}$} \\
\hline & \$/month & $\mathrm{c} / \mathrm{kWh}$ & $\$ / \mathrm{kW}$-month & & & \\
\hline Residential & 5 & 6.8 & () & 900 & 6300 & 1438 \\
\hline Commercial & 30 & 3.6 & 10) & 90 & 5400 & 1121 \\
\hline Industrial & 150 & 2.5 & 8 & 5 & $63(0)$ & 899 \\
\hline Totals & 8 & 4.3 & 5.3 & 995 & 18000 & 3458 \\
\hline
\end{tabular}

Typical of most utilities, this one has rate structures that differ substantially across customer classes. The residential customers pay no demand charge and have the highest average price $(7.7 \mathrm{c} / \mathrm{kWh})$. The commercial and industrial customers pay both energy and demand charges, with the industrial class paying less (leading to average prices of $6.7 \mathrm{c} / \mathrm{kWh}$ and $4.0 \mathrm{c} / \mathrm{kWh}$ for the commercial and industrial classes, respectively). The utility's total revenue is $\$ 1.1$ billion.

\section{Differences in DSM Across Customer Classes}

If this utility runs a set of DSM programs that reduce both energy and demand for each customer class by $1.0 \%$, the net lost revenues total $\$ 6.1$ million ( $0.6 \%$ of revenue). If the utility's DSM programs, however, emphasize one class over the others, then SR based on an aggregate model will not appropriately compensate the utility for its net lost revenues (Table 13). For example, if the percentage savings from the industrial DSM programs are $50 \%$ more than the savings achieved by the residential and commercial programs, then SR will overcompensate the utility, awarding it the same $\$ 6.1$ million for its loss of $\$ 5.6$ million, a $-0.04 \%$ error in total revenues. On the other hand, if the residential programs cut electricity use by $50 \%$ more than the commercial and industrial programs, then SR would 
undercompensate the utility, awarding it the same $\$ 6.1$ million for its loss of $\$ 6.4$ million, at $+(0.03 \%$ error in total revenues.

A DSM program aimed at only one customer class is the worst-case situation for SR (Table 13). An industrial-only program that cut aggregate energy and demand by the same $1 \%$ would result in \$3.0 million of lost revenue. But the aggregate SR model would paly the utility $\$ 6.1$ million, a $-(0.28 \%$ error in revenues. A DSM program that cut energy and demand by residential customers enough to save $1 \%$ overall would result in $\$ 8.3$ million of lost revenue. Once again, the aggregate SR model would pay the utility $\$ 6.1$ million, a $+0.20 \%$ error in revenues. Thus, a utility operating under SR with an aggregate model would have an incentive to target industrial customers and reglect residential customers in its DSM programs.

Table 13. Comparison of DSM-induced net lost revenues and the amounts awarded by statistical recoupling

Net lost revenue (million \$)

Actual SR-aggregate

Savings $50 \%$ higher in

Residential class

6.4

$6.1(+() .(13)$

Commercial class

6.2

$6.1(+(1.01)$

Industrial class

5.6

$6.1(-(0.04)$

Savings only in

Residential class

8.3

7.()

$6.1(+0.2())$

Commercial class

3.0

$6.1(+0.09)$

Industrial class

$6.1(-0.28)$

aThese cases all involve DSM programs that cut overall energy and demand hy $1 .(1 \%$. The numbers in parentheses are the percentage errors in the amounts of money awarded hy the SR model relative to total revenues ( $\$ 1,(096$ million).

"SR-aggregate refers to use of one statistical model that simulates electricity use for all three classes.

These cases of disproportionate DSM yield three conclusions:

- Use of an aggregate statistical model introduces some error into estimation of the amount of net lost revenues associated with DSM programs; use of statistical models for each customer class avoids this problem.

- The error caused by use of an aggregate model is small. Even in the worst possible situation (a DSM program aimed only at the industrial sector, where the lost 
revenues per $\mathrm{kWh}$ are the lowest), the amount of excess revenue granted the utility, while double the actual net lost revenues, is only $0.3 \%$ of total revenues.

- Therefore, states considering SR should either ensure roughly proportionate DSM across customer classes or use individual statistical models rather than the aggregate model.

\section{Differences in Conservation Load Factors}

DSM programs can also differ in their effects on customer energy use and peak demands. In the cases discussed above, energy and demand were always reduced by the same percentages, which assumes that the conservation load factor (CLF) is the same as the utility system's load factor.

However, DSM programs typically cut demand by a larger percentage than they cut energy use (i.e., the CLF is less than the system load factor). Consider a set of DSM programs that cut peak demands in each sector by $1 \%$ with different percentage reductions in energy use. Because residential customers pay no demand charge, actual net lost revenues equal those computed with SR models. For the commercial and industrial sectors, which pay both energy and demand charges, the SR models underestimate net lost revenues when the CLF of DSM programs is less than the system load factor (60\% in this example).

The extent to which the SR models underestimate net lost revenues depends on (1) whether the DSM programs cut peak demands at the time of maximum customer demand (i.e., the relationship between coincident and noncoincident peaks), (2) any nonzero shortterm avoided capacity costs, and (3) whether the utility's demand charge includes a ratchet." In the following analysis, I assume a zero avoided capacity cost and ignore differences between the timing of DSM-program demand reductions and customer peaks; these assumptions represent a worst-case treatment of SR. I treat the monthly demand charge parametrically, with a full 12-month ratchet at one extreme and no ratchet at the other.

If the DSM programs cut demand by $1 \%$ and cut energy use by $0.5 \%$ (i.e., the CLFF is half the system load factor), net lost revenues are $\$ 4.1$ million with a 12 -month ratchet and $\$ 3.1$ million with no ratchet, hut the SR model allows only $\$ 3.0$ million (a $-(0.1 \%$ error in total revenues with the ratchet and a $-(0.01 \%$ error with no ratchet). Figure 10 shows how the SR-induced error varies with differences in the CLF of the utility's DSM programs. Unlike the situation with different DSM effects across customer classes, the two types of SR models, by class and aggregate, yield the same errors. This error oc urs because the SR models estimate electricity sales (GWh) and are silent with respect to demand (MW). Therefore, changes in demand that do not affect sales have no effect on the amounts of net lost revenues estimated with SR models.

A A demand ratchet has a demand charge (\$/kW-month) based on the customer's highest demand during the past $\mathrm{n}$ months (where $\mathrm{n}$ is often 12), rather than the highest demand during the current month. 
Figure 10 shows that the SR estimate of lost revenue is increasingly inaccurate as CLF gets smaller. With a 12-month demand ratchet and a CLF of (1.1, the actual revenues lost are almost triple that calculated by the SR method. With no demand ratchet, the actual revenues exceed the SR estimate by $15 \%$. Figure 10 also shows the SR error as a percentage of total revenues. Because the amount of revenue lost is quite small for programs that save little energy per $\mathrm{kW}$ saved, these percentages are quite small. Even for DSM programs with a CLF of 0.1 and a 12 -month ratchet, the SR-induced error is less than $0.2 \%$ of revenues.

For two reasons, the errors in allowed revenues calculated here are upper bounds. First, I assumed that there is no short-term capacity cost that can be avoided by DSM programs. Second, utility load-management programs typically focus on reducing demands at the time of system peak, which may not coincide with the times of customer peak demands; therefore, the net lost revenue associated with demand charges will be less than assumed here.

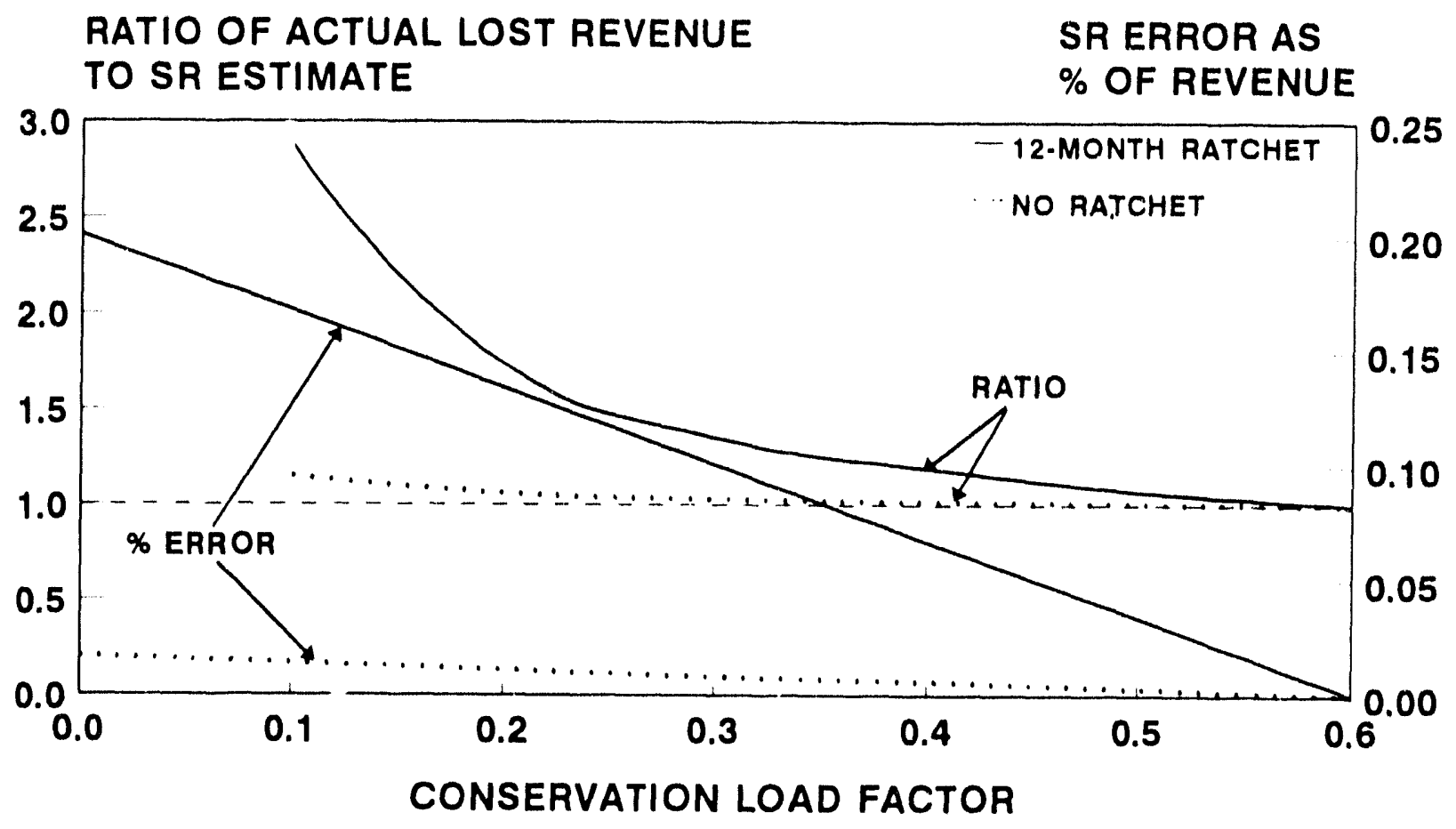

Fig. 10. Errors in the SR estimates of DSM-induced net lost revenue as functions of conservation load factor. (The system load factor is $\mathbf{0 . 6 ( 0 )}$.) The graph shows two sets of curves, both with a 12 -month ratchet and without a ratchet. The first set shows the ratio of actual lost revenues to the SR estimate, and the second set shows the SR error as a percentage of total revenues. 


\section{SHIFTS IN ELECTRICITY USE AMONG CUSTOMER CLASSES}

As discussed above, the models of aggregate electricity use perform better than does the combination of models of each customer class. In addition, it takes less time and is simpler to estimate one model than to estimate separate models for the residential, commercial, and industrial classes.

Although the mix of electricity use and demand across sectors changes from year to year, SR based on an aggregate model should produce unbiased estimates of allowed revenue. The variables that capture electricity use, number of customers, and electricity price all account for changes in the mix of sales, customers, and revenues across customer classes. Also, the proportions of electricity sales by customer class change only slowly over time (Fig. 11). Therefore, any errors caused by aggregate SR are likely to be quite small.

Even in Massachusetts, where the economy has been poor during the past few years, the shifts in electricity sales among classes have been slight. Between 1988 and 1992, for example, the share of NEES, sales to the industrial sector declined from $27.6 \%$ to $25.7 \%$, a two-percentage point change in four years.

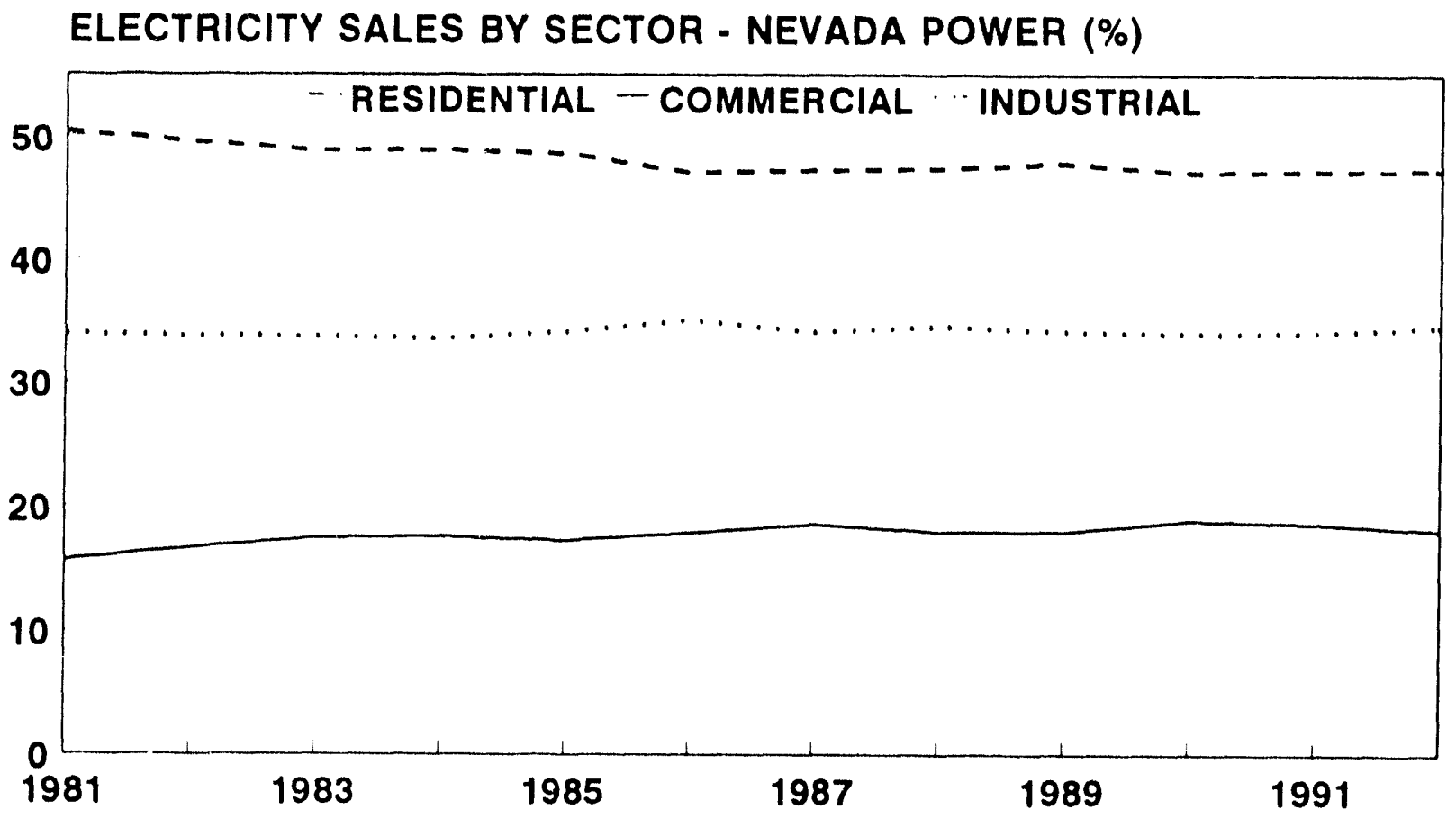

Fig. 11. The percentage contributions to total electricity sales by customer class for Nevada Power. 


\section{EXCLUSION OF SOME CUSTOMER CLASSES}

In this analysis of data from five utilities, I estimated models for the same three major customer classes, residential, commercial, and industrial. What are the consequences of ignoring electricity sales and revenues for the other customer classes, including street and highway lighting, other public authorities, and railroads and railways?

National data (Edison Electric Institute 1992) show that the three major classes accounted for more than $95 \%$ of total retail electricity sales during the past decade. Of course, the contributions of these classes to total sales differ across utilities. Among the five in this sample, the three classes account for anywhere from $93 \mathrm{to} 99 \%$ of total retail sales.

These data suggest that SR, based on inclusion of only the three major customer classes, can proceed in one of two ways. The utility can adjust electricity prices for all retail customer classes (including those excluded from the SR analysis), which will reduce slightly the SR-induced price changes. This approach makes sense if the utility's DSM programs affect these excluded customer classes. Alternatively, the utility could adjust electricity prices for only those classes that are explicitly included in the SR analysis. Because the three major customer classes account for such a large fraction of total retail sales, the difference between these two approaches is very small. 


\section{CONCLUSIONS}

\section{COMPARISON OF STATISTICAL RECOUPLING WITH OTHER MECHANISMS}

Statistical recoupling is only one of several methods that can be used to remove the disincentives that utilities face, under current regulation, to implement energy-efficiency programs. These approaches include explicit net-lost-revenue adjustment mechanisms and three forms of decoupling. The decoupling mechanisms include ones that recouple revenues to the determinants of fixed costs (e.g., California's Electric Revenue Adjustment Mechanism), to growth in the number of customers (revenue-per-customer decoupling), or to the determinants of electricity sales (SR). Not surprisingly, these methods have different strengths and limitations (Table 14).

All four approaches remove the disincentive to utility promotion of improved customer energy efficiency. With an NLRA, a utility's shareholders are compensated for the between-rate-cases net lost revenues caused by the utility's DSM programs. With decoupling, utility revenues are independent of sales levels.

The three decoupling methods, but not NLRAs, remove the incentive to promote load growth. Whether utilities should be encouraged to build load is a controversial issue. Some argue that, in a competitive environment, the utility (like other private companies) should earn more money if it sells more of its product. Others believe that, as part of integrated resource planning, the utility should earn more money for implementing its preferred resource plan, which likely will include both demand and supply resources. SR compensates utility shareholders for load growth that is a consequence of economic growth but not for "undifferentiated" load growth.

One of the concerns raised with decoupling is that it allows the utility to become less competitive and to worry less about controlling costs, promoting economic development, and providing top-notch customer service. Because NLRAs are narrowly focused on DSM programs, such mechanisms have no effect on the utility's competitive hehavior. In principle, the decoupling approaches, because they affect utility revenues rather than carmings, should not affect a utility's efforts to control costs. However, decoupling removes the incentive for load building, which removes the incentive for economic development that increases loads. Thus, utilities with ERAM or RPC decoupling might devote less effort to economic development in their service areas, although utilities with RPC decoupling have an ince.tive to add customers whose costs are less than that allowed in the RPC mechanism. SR, on the other hand, contains an explicit incentive for utilities to promote economic growth. This incentive is a consequence of the explanatory variable(s) used in the SR model(s) that capture local employment, industrial output, income, or gross state product. 
Table 14. Comparison of alternative methods to treat DSM-induced net lost revenues

\begin{tabular}{|c|c|c|c|c|c|}
\hline Criterion & NLRA & ERAM & RPC & SR & $\begin{array}{l}\text { Current } \\
\text { regulation }\end{array}$ \\
\hline $\begin{array}{l}\text { Removes disincentive to } \\
\text { energy-efficiency programs }\end{array}$ & Yes & Yes & Yes & Yes & No \\
\hline $\begin{array}{l}\text { Removes incentive to build } \\
\text { load }\end{array}$ & No & Yes & Yes & Yes & No \\
\hline \multirow{4}{*}{$\begin{array}{l}\text { Retains utility incentives to } \\
\text { - Control costs } \\
\text { - Promote economic } \\
\text { development } \\
\text { - Improve customer service }\end{array}$} & & & & & \\
\hline & Yes & Yes & Yes & Yes & Yes \\
\hline & Yes & No & Some & Yes & Yes \\
\hline & Yes & Yes & $?$ & Yes & Yes \\
\hline \multicolumn{6}{|l|}{ Simple to } \\
\hline - Administer & No & No & Yes & Yes & Yes \\
\hline Difficult to manipulate & No & Yes & Yes & Yes & Yes \\
\hline $\begin{array}{l}\text { Minimizes volatility of } \\
\text { electricity prices }\end{array}$ & Yes &. No & No & Yes & Yes \\
\hline $\begin{array}{l}\text { Maintains current risk } \\
\text { allocation between } \\
\text { customers and utility }\end{array}$ & Yes & No & No & Yes & Yes \\
\hline
\end{tabular}

Because RPC decoupling pays the utility a fixed amount per customer, the utility may have no incentive to encourage growth in the number of large customers (i.e., those for whom the cost of service is above the average). Although there was no evidence of this phenomenon occurring in Maine or Washington, some customers are concerned about this disincentive. However, RPC decoupling could be implemented separately for each customer class. Because the concept of revenue per customer is not part of either ERAM or SR, there is no reason for a utility to pay less attention to its large commercial and industrial customers. Thus, service quality is no more, nor less, of a problem with ERAM or SR than it is with traditional regulation.

Establishing and overseeing an NLRA can be very time consuming and complicated. On the other hand, this effort to establish an adequate DSM-program monitoring and 
evaluation system is needed anyway for good program management, for regulatory oversight, and for resource planning. California's ERAM is also complicated. On the other hand, RPC decoupling is very simple. SR may be difficult to understand, but it is straightforward to design and implement. With RPC decoupling, it may be necessary to agree on an estimate of per-customer growth in electricity use (expressed in \%/year). SR has no predetermined growth-rate factor that remains constant between rate cases.

One of the complications with an NLRA is the ease with which the utility can manipulate samples, data, analytical methods, and evaluation results. Because of the enormous information asymmetry between the utility and the PUC, monitoring the fairness of the NLRA's implementation can be difficult. The decoupling approaches are much less susceptible to manipulation."

An NLRA, because of its narrow focus on DSM programs, will have minimal effects on electricity prices. ERAM and RPC decoupling can lead to larger swings in prices. SR, because it seeks to mimic closely current regulation, should have only small year-to-year changes in electricity prices. However, SR relies on the accuracy of statistical models that are based on historical data. To the extent that the future is different from the past, SR will lead to errors in the amounts of money transferred to or from the utility. Thus, SR is vulnerable to major structural shifts in energy demand (e.g., tough new building or appliance standards or a new electrotechnology that sweeps the market).

ERAM and RPC decoupling transfer some risks from the utility to customers, those associated with sales fluctuations caused by changes in the weather and the economy. NLRA mechanisms shift DSM-program performance risks from a utility to its customers. The risks associated with weather and the economy remain with the utility under SR. With SR, customers bear the risk only for changes in revenues associated with those factors that affect sales and are not appropriately included in the SR equations.

In summary, statistical recoupling is similar to other forms of decoupling in that it eliminates the between-rate-cases incentive to build load and the disincentive to run energyefficiency programs. However, SR does not shift the revenue and price risks associated with weather and economic changes from utilities to customers. Thus, SR is likely to involve much smaller price changes than do other types of decoupling.

"Three reviewers of this report believe that development of the models for statistical recoupling will be contentious because people will assume that these models can be manipulated. Because the amounts of money at stake are large relative to earnings (although very small compared to revenues), they think that smart analysts will lind ways to manipulate the models. These people were not convinced by the examples summarized in Table 9 and Fig. 8. 


\section{FINAL THOUGHTS}

Whether or not SR is a good idea depends on two key factors. First, one has to believe that electric utilities can and should play a major role in helping their customers improve efficiency of electricity use. Second, one must believe that the betwen-rate-cases disincentive to DSM in current regulation is an important deterrent to aggressive and innovative utility DSM programs.

Acceptance of these two propositions leads to a commitment to remove from regulation the incentives for load growth and the disincentives for energy efficiency. As discussed here, utilities and regulatory commissions have several options to choose from in addressing this problem. These options include net-lost-revenue adjustments, various forms of decoupling, annual rate cases, alternative rate designs, and command-and-control regulation.

Compared with other approaches, SR offers important advantages. Its key strength is its ability to break the link between electric revenues and sales with minimal deviations from current ratemaking. In particular, SR shifts few risks from utilities to customers; therefore, the price swings caused by SR should be less than those caused by other decoupling approaches. SR should be easy to design and implement, primarily because it uses the same data and analytical techniques that utilities have used for years in developing short-term forecasting models. SR should be simple for regulators to oversee because its application is uncomplicated and it is difficult to manipulate the system. SR should serve utilities and their customers well in an era of increasing competition because SR retains an incentive for utilities to promote local economic growth. The major uncertainty with SR is the possibility that the determinants of electricity use will be different during the application period than during the historical period on which the models were based. If the structure of electricity use changes dramatically during the few years that SR is applied, then this approach could lead to nontrivial price changes.

On balance, statistical recoupling offers much potential to completely break the link between revenues and sales and therefore to free utilities to run ambitious and creative DSM programs. Statistical recoupling is easy to design, implement, and oversee; it should yield only small (much less than 2\%/year) changes in electricity price; and it retains the traditional incentives for utilities to control costs, promote economic development, and improve customer service.

\section{ACKNOWLEDGMENTS}

I thank Frank Farina and J. F. (Rick) Gilliam, Larry Tamashiro, Joseph Wharton and Alan Bailey, Arthur Canning, and Bill Wordley for sending me (and patiently explaining to me) the data they use in short-term forecasting. Eric Blank and David Moskovitz first suggested the basic concept that became statistical recoupling. Bruce Driver and Eric Blank helped me develop and advance these ideas in Colorado, Nevada, and Utah. David Berry, 
Eric Blank, Philip Carver, Robert Ciliano, Richard Collins, Alan Comnes, Audrey Curtiss, Joseph Eto, Frank Farina, Paul Galen, Corey Knutsen, Mark Kumm, David Moskovitz, Richard Parker, Thomas Power, Michael Reid, Don Schultz, and Richard Tempchin provided helpful comments on a draft of this report. Finally, I thank Fred O'Hara for editing the report and Ethel Schorn for navigating the final report through ORNL clearances and publication. 


\section{REFERENCES}

C. Bartsch and D. DeVaul 1993, "A Bright Idea for Industry," p. 16, Public Utilities Fortnightly 131(9), May 1.

Central Maine Power 1993, Report on Central Maine Power Company's Incentive Regulation Trial Program, Augusta, ME, March.

Colorado Public Utilities Commission 1993, Commission Decision and Order (1) Adopting Portions of a Settlement Agreement to be the Basis for Cost Recovery for DSM Programs That Stem from the DSM Collaborative Process and (2) Giving Directions Concerning Further Treatment of Certain Issues, Docket No. 91A-480EG, Decision No. C93-38, Denver, CO, January 13.

Connecticut Department of Public Utility Control 1991, Report to the General Assimbly, Department of Public Utility Control Implementation of Public Act 91-248, Docket No. 91-(1)720, New Britain, CT, December.

P. R. Corcoran 1993, "Prefiled Direct Testimony of Patrick R. Corcoran on Behalf of the Montana Power Company," Docket No. 93.6.24 before the Montana Public Service Commission, Butte, MT.

M. Cummings 1992, "DSM Incentives and Performance Measurement," pp. 291-298 in Proceedings, Fourth National Conference on Integrated Resource Planning, National Association of Regulatory Utility Commissioners, Washington, DC, September.

Edison Glectric Institute 1992, Statistical Yearbook of the Electric Utility Industry 1991, Washington, DC, October.

J. Eto, S. Stoft, and T. Belden 1993, The Theory and Practice of Decoupling, draft, LBL34555, Lawrence Berkeley Laboratory, Berkeley, CA, August.

F. Farina 1993, personal communication, Public Service Company of Colorado, Denver, CO, January.

Florida Power Corp. 1993, Proposal for Revenue Decoupling, St. Petersberg, FL, April.

J. F. Gilliam 1992, "Rebuttal Testimony Pursuant to Decision No. C92-1057," Docket No. 91A-480EG, Before the Colorado Public Utilities Commission, Public Service Company of Colorado, Denver, CO, September 14. 
E. Hirst 1992, "The Role of Evaluation When Electric Utilities Get Financial Incentives for Their DSM Programs," Evaluation Review 17(1), 93-1(17, February.

E. Hirst and E. Blank 1993, Regulating As If Customers Matter: Utility Incentives to Affect Load Growth, Land and Water Fund of the Rockies, Boulder, CO, January.

R. B. Lisbin 1993, personal communication, Pricing and Rate Planning Department, Southern California Edison, Rosemead, CA, January.

Maine Public Utilities Commission 1992, Investigation of Chapter 38 Filing of Central Maine Power Company, Docket No. 90-(085, Augusta, ME, October 28.

Maine Public Utilities Commission 1993, Order Approving Stipulation, Docket Nos. 90-(085-A, 90-085-B, 92-174, and 92-346, Augusta, ME, February 5.

C. Marnay and G. A. Comnes 1990, Ratemaking for Conservation: The California ERAM Experience, LBL-28019, Lawrence Berkeley Laboratory, Berkeley, CA, March.

C. Marnay and G. A. Comnes 1992, "California's ERAM Experience," Chapter 3 of Regulatory Incentives for Demand-Side Management, American Council for an EnergyEfficient Economy, Washington, DC.

D. Moskovitz 1989, Profits and Progress Through Least-Cost Planning, National Association of Regulatory Utility Commissioners, Washington, DC, November.

D. Moskovitz, C. Harrington, and T. Austin 1992, "Weighing Decoupling vs Lost Revenues: Regulatory Considerations," The Electricity Journal 5(9), 58-63, November.

D. Moskovitz, C. Harrington, and T. Austin 1993, Decoupling: Risks and Price Volatility, Regulatory Assistance Project, Gardiner, ME, June.

S. N. Nadel, M. W. Reid, and D. R. Wolcott (Eds.) 1992, Regulatory Incentives for DemandSide Management, American Council for an Energy-Efficient Economy, Washington, DC.

P. Newman, S. Kihm, and D. Schoengold 1992, "Spare the Stick and Spoil the Carrot: Why DSM Incentives for Utility Stockholders Aren't Necessary," Chapter 11 in Regulatory Incentives for Demand-Side Management, American Council for an Energy-Efficient Economy, Washington, DC.

Oregon Public Utility Commission 1992, In the Matter of the Investigation into Electric Utility Incentives for Acquisition of Conservation Resources, Order No. 92-1673, Salem, OR, November 23.

PacifiCorp 1993, Report of PacifiCorp Decoupling Collaborative, Portland, OR, May. 
Portland General Electric 1993, Decoupling Collaborative Final Report, Portland, OR, April.

Potomac Electric Power Company 1993, "The Application of Potomac Electric Power Company for an Increase in its Retail Rates for the Sale of Electric Energy, Before the District of Columbia Public Service Commission, Washington, DC, June 4.

M. Quinlan 1993, personal communication, Connecticut Department of Public Utility Control, New Britain, CT, April.

M. W. Reid, J. B. Brown, and J. C. Deem 1993, Incentives for Demand-Side Management, second edition, Barakat \& Chamberlin, Inc., prepared for the National Association of Regulatory Utility Commissioners, Washington, DC, March.

B. Smith 1992, personal communication, Revenue Requirements Department, Pacific Gas and Electric Company, San Francisco, CA, December.

R. S. Sonstelie 1993, "Supplemental Testimony," Docket No. UE-921262 Before the Washington Utilities and Transportation Commission, Puget Power, Bellevue, WA, January.

Southern California Edison 1992, Demand Side Management Annual Program Summary Report, 1991 Results, 1992 Plans, Rosemead, CA, March.

Southern California Edison 1993, Short Range Forecast ECAC 1994 Work Papers, Docket No. 93-(05-(044 Before the California Public Utilities Commission, Rosemead, CA, May.

E. A. Stellwagen and R. L. Goodrich 1993, Forecast Pro for DOS, Business Forecast Systems, Belmont, MA, February.

S. Swanson 1992, "Testimony on Behalf of the Land and Water Fund of the Rockies and the Colorado Office of Energy Conservation Before the Colorado Public Utilities Commission," Docket No. 91A-480EG, Denver, CO, September 8.

S. Switzer 1993, personal communication, Baltimore Gas and Electric Company, Baltimore, MD, April.

L. Tamashiro 1993, personal communication, Nevada Power Company, Las Vegas, NV, February.

M. Tighe 1993, personal communication, Maryland Public Service Commission, Baltimore, MD, April.

M. Townsley 1993, personal communication, Northeast Utilities, Hartford, CT, April. 
U.S. Environmental Protection Agency 1993, Conservation Verification Protocols, A Guidance Document for Electric Utilities Affected by the Acid Rain Program of the Clean Air Amendments of 1990, EPA 430/8/B-92-0(12, Washington, DC, March.

Vermont Public Service Board 1990, Investigation into Least-Cost Investments, Enengy Efficiency, Conservation and Management of Demand for Energy, Docket No. 5270, Montpelier, VT, April 16.

Washington Utilities and Transportation Commission 1991, In the Matter of the Petition of Puget Sound Power \& Light Company for an Order Approving a Periodic Rate Adjustment Mechanism and Related Accounting, Docket Nos. UE-901183-T and UE-901184-P, Olympia, WA, April 1.

Washington Utilities and Transportation Commission 1992, First Supplemental Order Rejecting Tariff Filing; Authorizing Refiling, Docket No. UE-92(0630, Olympia, WA, September 24.

J. B. Wharton 1993, personal communication, Load Forecasting \& Special Projects, New England Power Service Company, Westborough, MA, February.

T. Woolf 1993, personal communication, Tellus Institute, Boston, MA, April.

W. Wordley 1993, personal communication, PacifiCorp, Portland, OR, April.

M. A. Ziering 1986, Risk, Retum, and Ratemaking: A Review of the Commission's Regulatory Mechanisms Pursuant to D.85-12-078, California Public Utilities Commission, San Francisco, October. 


\section{ALTERNATIVE MODELS OF TOTAL ELECTRICITY USE FOR PACIFICORP}

The models summarized in Table 9 and Fig. 8 are presented below. These tables are the outputs from Forecast Pro, the software used to estimate these time-series models. CTOT is the number of customers, PTOT is the average retail electricity price in real (1987) dollars, HDD and CDD are heating and cooling degree days, INDOUT is Utah industrial output, EMPMFG is manufacturing employment in Utah,_CONST is the constant term, AUTO[-1] is the first-order autoregressive term, and Ln refers to the logarithmic form of the variable. R-square and Adjusted R-square show the percentage of variation explained by the model. BIC is the Bayes information criterion. The Durbin-Watson d-statistic and the Ljung-Box test check for autocorrelation in the residual terms. MAPE is the mean absolute percentage error. And RMSE is the root-mean-squared error.

\begin{tabular}{lrrrr} 
1. Forecast Model: Total Utah Sales & (GWh) \\
Term & Coefficient & Standard error & t-statistic & Significance \\
\hline CTOT & 0.006603 & 0.001354 & 4.875088 & 0.999982 \\
PTOT & -61.723168 & 31.555730 & -1.956005 & 0.942527 \\
HDD & 0.113035 & 0.013195 & 8.566718 & 1.000000 \\
CDD & 0.346906 & 0.035360 & 9.810710 & 1.000000 \\
INDOUT & 176.921646 & 111.595417 & 1.585385 & 0.879246 \\
CONST & -563.573372 & 334.283099 & -1.685916 & 0.900402 \\
AUTO -1 1] & 0.415613 & 0.1482 .75 & 2.802979 & 0.992229 \\
\hline
\end{tabular}

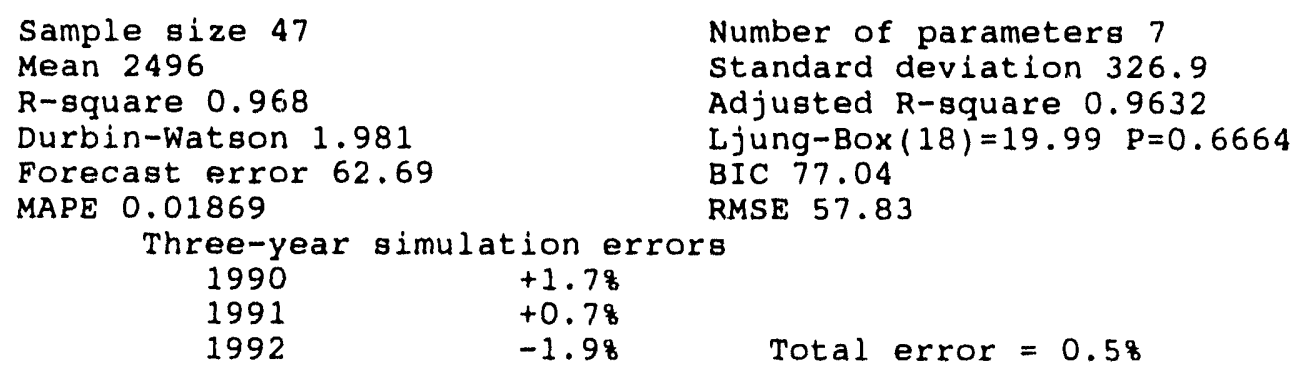


2. Forecast Model: Total Utah Sales (GWh)

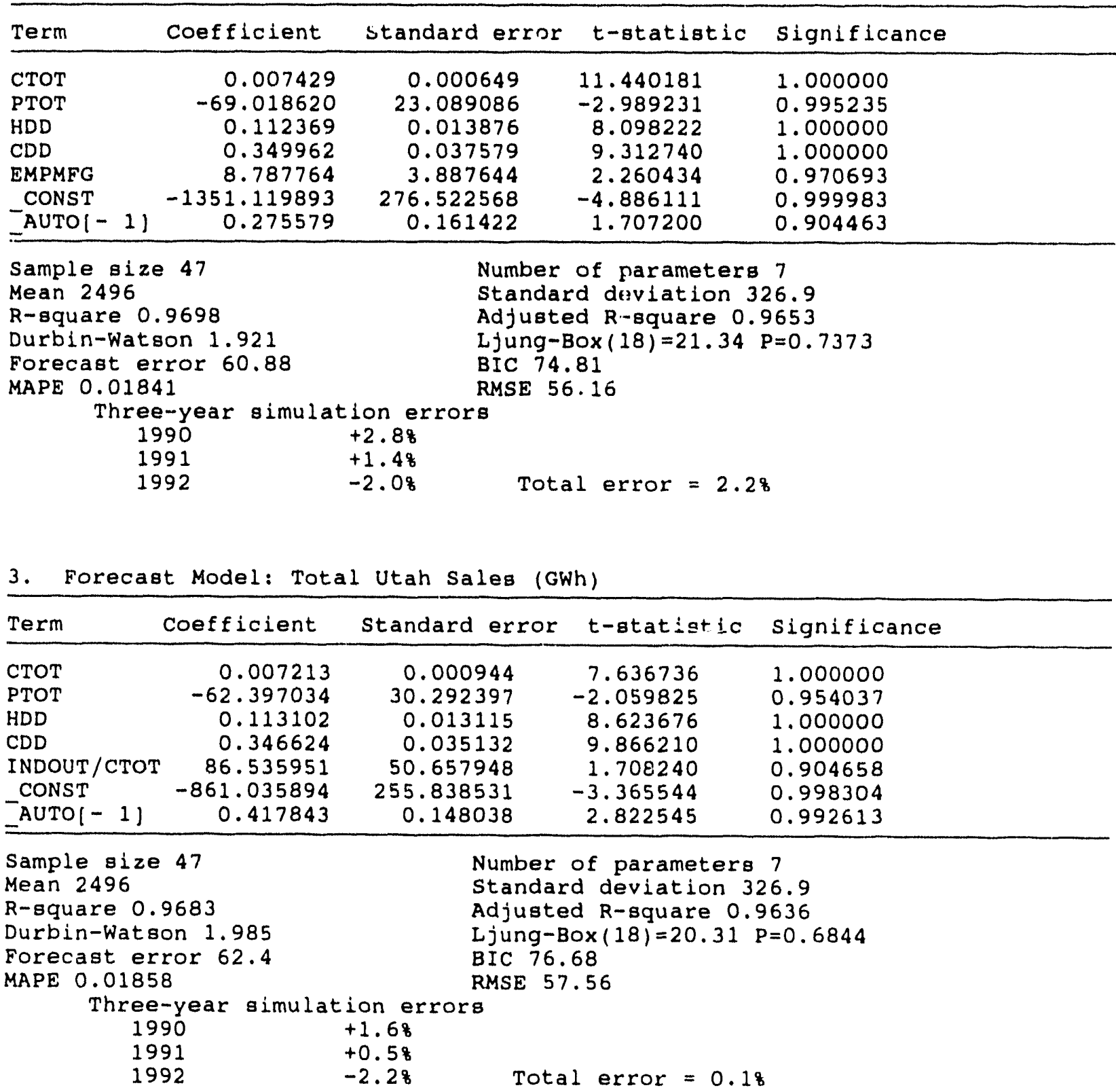


4. Forecast Model: Total Utah Sales (GWh) (Log transform)

\begin{tabular}{lrrrr}
\hline Term & Coefficient & Standard error & t-statistic & significance \\
\hline Ln(CTOT) & 1.238864 & 0.213670 & 5.798027 & 0.999999 \\
Ln(PTOT) & -0.153025 & 0.069808 & -2.192072 & 0.965745 \\
HDD & 0.000047 & 0.000005 & 8.540861 & 1.000000 \\
CDD & 0.000142 & 0.000015 & 9.663676 & 1.000000 \\
Ln(INDOUT) & 0.102805 & 0.077822 & 1.321033 & 0.806002 \\
CONST & -8.148596 & 2.663202 & -3.059699 & 0.996056 \\
AUTO(-1) & 0.370750 & 0.152165 & 2.436505 & 0.980625 \\
\hline
\end{tabular}

Sample gize 47

Mean 7.814

R-square 0.9686

Durbin-Watson 1.983

Forecast error 0.02522

MAPE 0.01915

Three-year simulation errors

$\begin{array}{lll}1990 & +2.78 \\ 1991 & +2.38 \\ 1992 & +0.18 & \end{array}$

5. Forecast Model: Total Utah Sales per Customer (kWh)

\begin{tabular}{lrrrr}
\hline Term & Coefficient & Standard error & t-statistic & Significance \\
\hline PTOT & -94.840847 & 64.463149 & -1.471241 & 0.851140 \\
HDD & 0.262514 & 0.028798 & 9.115726 & 1.000000 \\
CDD & 0.793193 & 0.076713 & 10.339750 & 1.000000 \\
INDOUT & 560.396888 & 100.023316 & 5.602663 & 0.999998 \\
CONST & 4699.238795 & 510.335709 & 9.208132 & 1.000000 \\
AUTOl- 1) & 0.492139 & 0.140957 & 3.491423 & 0.998835 \\
\hline
\end{tabular}

Sample size 47

Mean 5707

R-square 0.8512

Durbin-Watson 2.059

Forecast error 143.3

MAPE 0.01933

Three-year simulation error

$\begin{array}{ll}1990 & +2.08 \\ 1991 & +0.98 \\ 1992 & -1.58\end{array}$

$-1.58$
Number of parameterg 7

standard deviation 0.1328

Adjusted R-square 0.9639

Ljung-Box (18) $=17.57 \quad P=0.516$

BIC 76.72

RMSE 58.61

Total error $=5.18$

Number of parameters 6

Standard deviation 350.8

Adjusted R-square 0.833

Ljung-Box $(18)=20.77 \quad \mathrm{P}=0.7086$

BIC 171.2

RMSE 133.9

Total error $=1.48$ 
6. Forecast Model: Total Utah Sales per Customer (kWh)

\begin{tabular}{lrrrr}
\hline Term & Coefficient & standard error & t-statiotic & significance \\
\hline PTOT & -77.908581 & 63.924633 & -1.218757 & 0.770097 \\
HDD & 0.260320 & 0.030097 & 8.649273 & 1.000000 \\
CDD & 0.790214 & 0.080359 & 9.833496 & 1.000000 \\
EMPMFG & 38.238323 & 7.111025 & 5.377329 & 0.999997 \\
CONST & 2137.989280 & 886.464513 & 2.411816 & 0.979565 \\
AUTO(-1) & 0.465573 & 0.145612 & 3.197345 & 0.997328 \\
\hline
\end{tabular}

Sample size 47

Mean 5707

R-square 0.8421

Durbin-Watson 2.001

Forecast exror 147.7

MAPE 0.02031

Three-year simulation error

$\begin{array}{ll}1990 & +2.68 \\ 1991 & +0.48 \\ 1992 & -3.98\end{array}$

$-3.98$
Number of parameters 6

Standard deviation 350.8

Adjusted R-square 0.8228

Ljung-Box $(18)=18.96 \quad P=0.6057$

BIC 176.3

RMSE 137.9

Total error $=-0.98$

7. Forecast Model: Total Utah Sales per Customer (kWh)

\begin{tabular}{lrrrr}
\hline Term & Coefficient & standard error & t-statistic & significance \\
\hline PTOT & -87.482583 & 77.156850 & -1.133828 & 0.736547 \\
HDD & 0.265101 & 0.027561 & 9.618740 & 1.000000 \\
CDD & 0.788912 & 0.073277 & 10.766149 & 1.000000 \\
INDOUT/CTOT & 351.254641 & 78.939624 & 4.449662 & 0.999935 \\
CONST & 4215.013094 & 710.312774 & 5.934024 & 0.999999 \\
-AUTOI- 1) & 0.586401 & 0.131043 & 4.474858 & 0.999940 \\
\hline
\end{tabular}

Sample size 47

Mean 5707

R-square 0.8485

Durbin-Watson 2.157

Forecast error 144.6

MAPE 0.01923
Number of parameters 6

Standard deviation 350.8

Adjusted R-square 0.83

Ljung-BOX $(18)=22.25 \quad \mathrm{P}=0.7791$

BIC 172.7

RMSE 135.1

Three-year simulation errors

$\begin{array}{ll}1990 & +1.68 \\ 1991 & +0.18 \\ 1992 & -2.48\end{array}$

Total error $=-0.7 \%$ 
8. Forecast Model: Total Utah Sales per Customer ( $k$ Wh) (Log transform)

\begin{tabular}{|c|c|c|c|c|c|}
\hline Term & Coefficient & Standard & error & $t$-gtatistic & Significance \\
\hline $\begin{array}{l}\text { Ln (PTOT) } \\
\text { HDD } \\
\text { CDD } \\
\text { Ln (INDOUT) } \\
\text { CONST } \\
=\text { AUTO }(-1)\end{array}$ & $\begin{array}{r}-0.118210 \\
0.000047 \\
0.000140 \\
0.184214 \\
8.655771 \\
0.461057 \\
\end{array}$ & $\begin{array}{l}0.066 \\
0.000 \\
0.000 \\
0.031 \\
0.129 \\
0.143 \\
\end{array}$ & $\begin{array}{l}328 \\
005 \\
014 \\
288 \\
577 \\
213 \\
\end{array}$ & $\begin{array}{r}-1.782202 \\
9.028772 \\
10.158988 \\
5.887621 \\
66.800403 \\
3.219389 \\
\end{array}$ & $\begin{array}{l}0.917877 \\
1.000000 \\
1.000000 \\
0.999999 \\
1.000000 \\
0.997486 \\
\end{array}$ \\
\hline \multicolumn{3}{|c|}{$\begin{array}{l}\text { Sample size } 47 \\
\text { Mean } 8.648 \\
\text { R-square } 0.8485 \\
\text { Durbin-Watson } 2.074 \\
\text { Forecast error } 0.02518 \\
\text { MAPE 0.01931 } \\
\text { Three-year simulation errors } \\
1990 \\
1991 \\
1992\end{array}$} & \multicolumn{3}{|c|}{$\begin{array}{l}\text { Number of parameters } 6 \\
\text { Standard deviation } 0.06107 \\
\text { Adjusted } R-8 q u a r e 0.8301 \\
\text { Ljung-Box }(18)=20.39 \quad \mathrm{P}=0.6886 \\
\text { BIC } 171.3 \\
\text { RMSE } 133.4 \\
\text { a } \\
\quad \text { Total error }=1.48\end{array}$} \\
\hline
\end{tabular}


ORNL/CON-372

\section{INTERNAL DISTRIBUTION}

1. D. Baucr

2. V. D. Baxter

3. L. Berry

4. D. S. Bjornstad

5. M. A. Brown

6. J. B. Cannon

7. R. S. Carlsmith

8. F. C. Chen

9. J. Christian

10. G. Courville

11. P. D. Fairchild

12. W. Fulkerson

13. M. B. Gettings

14. C. W. Hagan

15. L. J. Hill

16. E. Hillsman

17. E. Hirst

18. P. J. Hughes

19. C. R. Kerley

20. J. O. Kolb
21. M. A. Kuliasha

22. R. Lee

23. P. Leiby

24. J. M. MacDoniald

25. V. C. Mei

26. W. R. Mixon

27. S. Purucker

28. D. E. Reichle

29. D. T. Rizy

30. M. Schweitzer

31. R. B. Shelion

32. J. N. Stone

33. J. Van Dyke

34. J. M. Veigel (ORAU)

35. D. L. White

36. T. J. Wilbanks

37. ORNL patent Olfice

38. Central Rescarch Olfiec

39. Document Reference Section

40. Laboratory Records (RC)

41-43. Laboratory Records Dept.

\section{EXTERNAL DISTRIBUTION}

44. Dr. Douglas R. Bohi, Director, Encrgy and Natural Resources Division, Rescources for the Future, 1616 P Street, N.W., Washington, DC 2(k)36

45. Dr. Thomas E. Drabek, Professor, Department of Sociolegy, University of Denver, Denver, Colorado 80208-(1209

46. Calvin MacCracken, President, Calmac Manufacturing Corporation, 101 West Sheffield Avenue, P. O. Box 710, 1Englewood, NJ 07631

47. Jacqueline B. Shrago, Director, Office of Technology Transfer, $4(15$ Kirkland Hall, Vanderbilt University, Nashville, TN 37240

48. Mr. George F. Sowers, P. E., Senior Vice President, Law Companics Group, Inc., 114 Townpark Drive, Suite 250, Kennesaw, Georgia 30144-5529

49. Dr. C. Michael IValton, Paul D. and Betly Robertson Meck Centennial Professor and Chairman, Department of Civil Engineering, College of Enginecring, The University of Texas at Austin, Cockrell Hall, Suite 4.2, Austin, Texas 78712

50.-51. OSTI, U. S. Department of Energy, P. O. Box 62, Oak Ridge, Tennessece 37831

52. Office of Assistant Manager for Energy Rescarch and Development, DOE/ORO, P. O. Box 2(K)1 Oak Ridge, TN 37831-86(K)

53.-95(). External Energy Efficiency and Renewables Section Distribution Mailing List and extra copies to E.M. Schorn, $45(x) \mathrm{N}, \mathrm{H}-19 \mathrm{~A}$ 


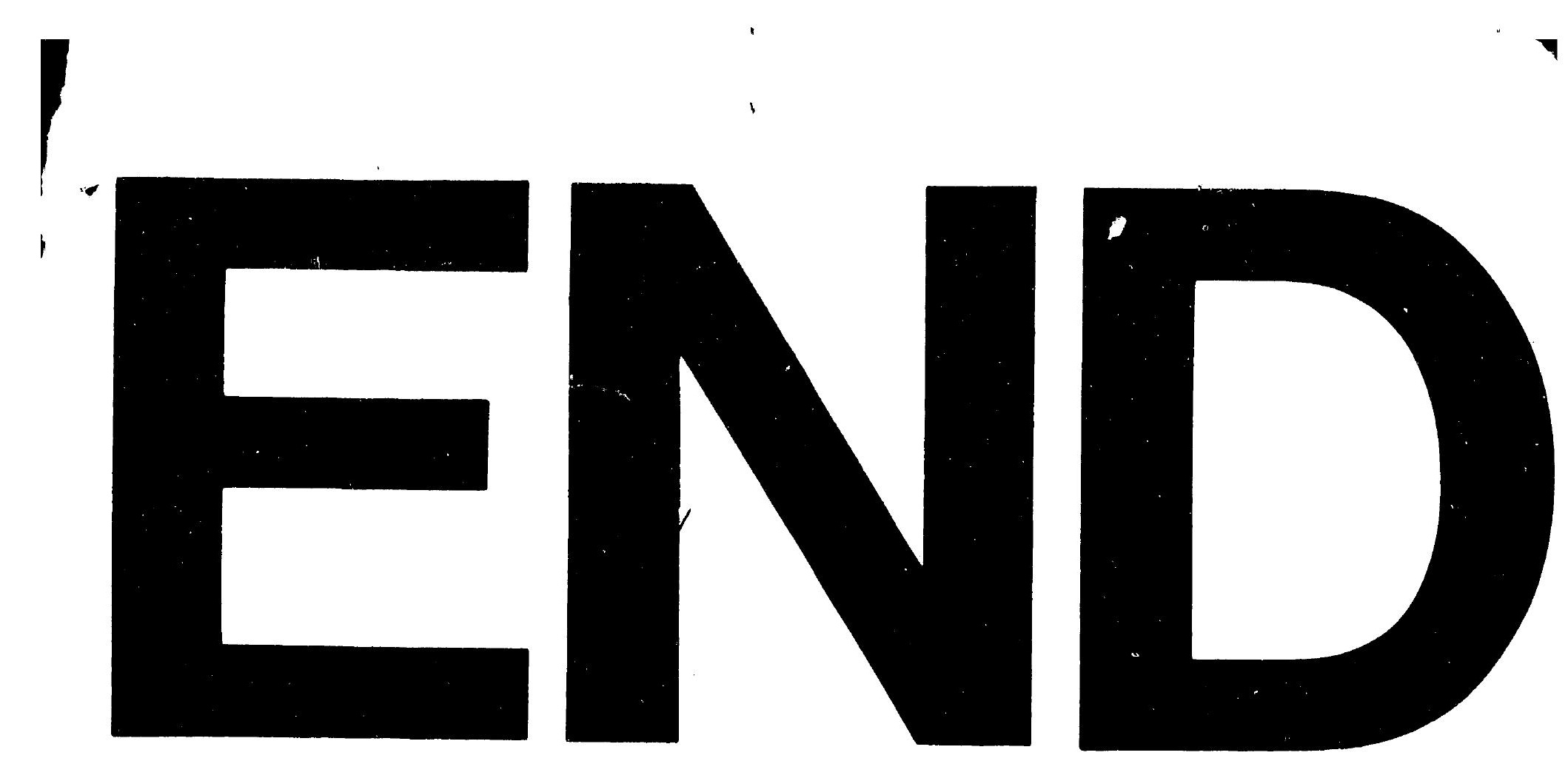


